\title{
CHARACTERISATION OF SPATIAL AND TEMPORAL VARIABILITY OF RF-EMF EXPOSURE LEVELS IN URBAN ENVIRONMENTS IN FLANDERS, BELGIUM
}

Maarten Velghe ${ }^{\mathrm{a}}$, Wout Joseph ${ }^{\mathrm{a}}$, Senne Debouvere ${ }^{\mathrm{a}}$, Reza Aminzadeh ${ }^{\mathrm{a}}$, Luc Martens ${ }^{\mathrm{a}}$ and Arno Thielens ${ }^{\mathrm{a}, \mathrm{b}}$

a Department of Information Technology, Ghent University/IMEC, Technologiepark 15, Ghent 9052, Belgium

${ }^{\mathrm{b}}$ Berkeley Wireless Research Center, Department of electrical engineering and Computer Sciences, University of California, Berkeley, 2108 Allston Way, Suite 200, Berkeley, CA 94704, United States of America

Keywords: Radio-Frequency electromagnetic Fields, Personal exposure, Microenvironmental Research

\begin{abstract}
Personal exposure to Radio-Frequency Electromagnetic Fields (RF-EMFs) was studied using personal measurements in five different microenvironments in each of five cities (Brussels, Antwerp, Ghent, Bruges and Hasselt) in Flanders, Belgium. These measurements were carried out by two researchers using on-body calibrated personal exposimeters. In three out of the five studied cities (Brussels, Ghent and Bruges), temporal aspects of personal exposure to RF-EMFs were studied as well. Measurements during and outside of rush hours (7:00 - 9:15 and 16:30 19:00) were compared. Likewise, measurements were executed during night time and compared to the ones measured during working hours. Representativeness and repeatability of the measurement method was studied as well. The highest mean total exposure was found in Brussels $\left(2.63 \mathrm{~mW} / \mathrm{m}^{2}\right)$, the most densely populated city in this study. However, we measured higher downlink exposure in Antwerp than in Brussels, which might be an effect of the stronger legislation on base stations in Brussels. The measurements and used protocol were found to be both repeatable over time ( $\mathrm{r}=0.95$ for median total exposure) and representative for the studied microenvironments in terms of path selection $(\mathrm{r}=0.88$ for median total exposure). Finally, in 10 out of the 13 on-body calibrated frequency bands we found that the measurement devices underestimate the intensity of the incident RF-EMFs with median underestimations up to $68 \%$.
\end{abstract}

\section{Introduction}

Mobile communication devices and base stations are omnipresent in our society and use radiofrequency electromagnetic fields (RF-EMFs) to communicate. RF-EMFs can cause thermal effects in the human body (ICNIRP, 1998). Therefore, personal exposure to RF-EMFs is studied. Previous publications have aimed to characterize exposure levels in the general population and multiple methods for measuring this exposure have been proposed. Exposure can be measured relatively accurately using immobile tri-axial antenna systems in combination with a spectrum analyser (Joseph \& Verloock, 2010; Joseph et al., 2009). This method has the disadvantage that spatial measurements are very time consuming. Personal exposure can practically only be measured using handheld or wearable instruments. Commonly used devices for such measurements are personal exposimeters (PEMs) (e.g., Bhatt et al., 2016; Bolte, 2016; 
Thielens et al., 2018). These are body-worn devices that register exposure in several frequency bands used for telecommunication. A protocol for the use of these devices has been proposed in Röösli et al. (2010). Using this protocol, public exposure to RF-EMFs has been measured in different microenvironmental exposure studies. Microenvironments are spatially defined areas or trajectories characterised by population density, the type of local activity of individuals, and potentially other factors that have an influence on the RF-EMF exposure. Examples are outdoor urban areas or trajectories of public transport (Röösli et al., 2010). In such studies, different geographical study areas are divided in these categories and typically a path through the area is then defined along which a trained researcher, wearing a PEM, measures the exposure for a number of times (Bhatt et al., 2016; Sagar et al., 2016; Thielens et al., 2018; Urbinello et al., 2014c). In comparison to volunteer studies this method has the advantage that the researcher can be trained in a measurement protocol that reduces measurement uncertainties. A researcher can control self-induced exposure, the location of the device on the body, and will follow predefined paths precisely. This reduces variability (Neubauer et al., 2010).

To prevent possible health effects of RF EMFs, guidelines for exposure limits have been proposed by the International Commission on Non-Ionizing radiation Protection (ICNIRP) (for example: $41 \mathrm{~V} / \mathrm{m}$ for $900 \mathrm{MHz}, 58 \mathrm{~V} / \mathrm{m}$ for $1800 \mathrm{MHz}$, and $61 \mathrm{~V} / \mathrm{m}$ for $2100 \mathrm{MHz}$ ) (ICNIRP, 1998). These guidelines are used by governments to determine regulatory limits on the output power of base station antennas and exposure levels caused by those antennas. However, the effect of different regulations is not often studied. Since telecommunication companies want to provide an optimal service to their users, stricter precautionary limits on antennas might lead them to place more antennas, lower the mast height and adapt the antenna tilt (Urbinello et al., $2014 b$ ). Although this would lead to lower peak values in the neighbourhood of the antennas, it might lead to a higher mean exposure in the environment (Urbinello et al., 2014b). Urbinello et al. (2014b) performed a study in Amsterdam, Brussels, Ghent, and Basel and found no significant effects of different regulations. In a relatively small area as Flanders there are multiple densely populated cities with similar characteristics regarding population, architecture, climate, and telecommunication providers. This presents an opportunity to assess different factors influencing population exposure, such as population density. Moreover, the Brussels Capital Region has its own legislation which is significantly stricter than the one in the Flemish Region. So a potential effect of legislation could be investigated and compared for Brussels and cities in the Flemish Region. Exposure in Flanders has been investigated using population surveys (e.g. Joseph et al., 2008). However, a systematic comparison between Flemish cities using the more reliable microenvironmental measurements has not yet been performed.

Previous studies have compared personal exposure in different microenvironments and different cities to determine other influencing factors. Bhatt et al. (2016) compared two cities (Melbourne and Ghent), Sagar et al. (2016) compared different cities in Switzerland, and Sagar et al. (2018) studied personal exposure in six countries from five different continents. These studies found that exposure is usually higher in more densely populated areas.

Microenvironmental studies have uncertainties as well. First, it is typically assumed in those studies that temporal variations are not significant. However, exposure varies due to changes 
in the environment and number of users (Joseph \& Verloock, 2010; Joseph et al., 2009). Aerts et al. (2018) found that the short-term temporal bias can be reduced by up to $40 \%$ when averaging over one hour. Other studies assessing temporal variations are scarce (e.g., Mahfouz et al. (2012)). Bolte \& Eikelboom, (2012) and Birks et al. (2018) used personal survey studies with volunteers (adults and children, respectively) to analyse time variations in exposure across one week and between day and night, respectively. However, personal exposure measurements by a trained researcher are more controlled and lead to less uncertainties. For convenience, these are typically limited to office hours (e.g., Thielens et al., 2018; Urbinello et al., 2014a). It is an open question how these can be extrapolated to other times of day. Uncertainties and underestimations when measuring with a PEM also arise from body shielding (Aminzadeh et al., 2018; Bolte, 2016; Thielens et al., 2015, Bhatt et al., 2016a). These could be reduced by performing an on-body calibration (Bolte, 2016; Thielens et al., 2015). Although it is recommended to calibrate data obtained using PEMs, in most studies this is lacking. There is also a debate about the reproducibility of the results. Most studies do not test for repeatability and representativeness of the chosen method. Proposed methods using repeated measurements, paths of minimal lengths, and comparisons of different paths within the same microenvironment have been applied to demonstrate repeatability (Sagar et al., 2016; Thielens et al., 2018; Urbinello et al., 2014c). However, it is uncertain whether these methods apply to all environments. In this study we incorporate recommendations from these studies and furthermore, show the repeatability and representativeness of the presented results.

The goal of this paper was to measure spatial and temporal variations in personal RF-EMF exposure in urban environments in Flanders. The novelties of this study were to: i) for the first time, compare personal exposure levels between five of the largest cities in Flanders, using comparable microenvironments to represent each city, ii) determine the effect of legislation on exposure, iii) assess the temporal variability of personal exposure in three of these cities including, in contrast to previous studies, measurement times outside of office hours, iv) perform an on-body calibration of the used measurement device, the ExpoM-RF, and v) evaluate repeatability and representativeness of personal RF-EMF exposure measurements.

\section{Materials and methods}

The measurements in this study consisted of two parts: measurements designed to assess spatial variations, e.g. comparing personal exposure in different cities, and measurements designed to assess temporal variations, e.g. exposure during rush versus during non-rush hours. The study consisted of three measurement campaigns: one between October $28^{\text {th }}$ and November $26^{\text {th }} 2017$, a second between February $15^{\text {th }}$ and March $15^{\text {th }} 2018$, and a third between January $14^{\text {th }}$ and $19^{\text {th }}$ 2019. All spatial measurements were conducted by one researcher during the first two measurement campaigns and all temporal measurements by a second researcher during all three measurement campaigns. The next paragraphs discuss the measurement procedures, studied areas and timeslots, and the data post-processing. 


\subsection{Measurement device}

The ExpoM-RF (Fields at work GmbH, Zürich, Switzerland) was used for all measurements conducted in this study. The device has user-defined measurement sampling intervals from $3 \mathrm{~s}$ to $6000 \mathrm{~s}$ and allows marking the data. In combination with a measurement diary kept by the researchers, this facilitated post-processing. The ExpoM-RF registered RF-EMF field strengths in $\mathrm{V} / \mathrm{m}$. Table A1 in Appendix A gives an overview of the frequency bands measured by the device and their respective upper and lower limits of detection (LOD).

\subsection{Study areas, protocol, and design}

All measurements in this study only involved exposure induced by devices from users in the general population (excluding the ones of the researchers) the network antenna base stations, and broadcast antennas. In order to achieve this, during all measurements, any mobile devices carried by the researchers were shut down in order not to contribute to the data.

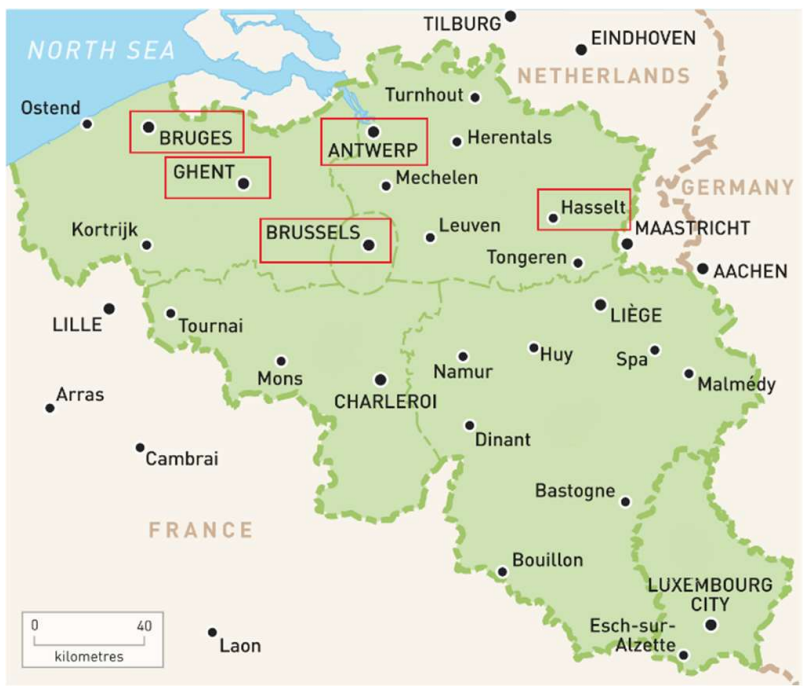

Figure 1: Map of Belgium showing Antwerp, Bruges, Brussels, Ghent, and Hasselt (obtained from: https://www.roughguides.com)

\subsubsection{Spatial measurements}

The spatial measurements were conducted in diverse types of microenvironments (Röösli et al., 2010) in five of the largest cities in the Flemish Region and the Brussels Capital Region: Antwerp, Bruges, Brussels, Ghent, and Hasselt (Figure 1 and Appendix B). Table B1 shows the population densities of these cities from the highest to the lowest population density. Four of these (Antwerp, Bruges, Ghent, and Hasselt) fall under the Flemish legislation for RF-EMF exposure, whilst Brussels falls under the legislation of the Brussels Capital Region. Table 1 shows the exposure limits for both regions. The cumulative norm is about 10 times stricter in the Brussels Capital Region than it is in Flanders. Additionally Flanders has a norm per antenna for indoor exposure. In each of the studied cities, five matching microenvironments were defined (Table B2, Appendix B: an industrial, residential, park and recreation, train station, and shopping area. These areas were selected to cover different activities in order to have a 
good basis to compare the selected cities. Similar types of microenvironments were also considered in other studies in this field (Urbinello et al., 2014b; Bhatt et al., 2016a; Thielens et al., 2018).

Table 1: Local regulations of RF-EMF exposure limits in terms of power density for Flanders and Brussels ${ }^{a, b, c}$. (Flemish Region, 2010; Brussels Capital Region, 2013)

\begin{tabular}{lccc}
\hline \multirow{2}{*}{ Frequency range (MHz) } & \multicolumn{2}{c}{ Flanders $\left(\mathbf{m W} / \mathbf{m}^{2}\right)$} & Brussels $\left(\mathbf{m W} / \mathbf{m}^{2}\right)$ \\
& Cumulative & $\begin{array}{c}\text { Per antenna } \\
\text { (indoor) }\end{array}$ & Cumulative \\
\hline $10-400$ & 498 & 11 & 43 \\
$400-2000$ & $1.2 * \mathrm{f}$ & $0.027 * \mathrm{f}$ & $0.107 * \mathrm{f}$ \\
$2000-10000$ & 2500 & 53 & 220 \\
\hline
\end{tabular}

${ }^{a} \mathrm{f}$ is the frequency of the signal in $\mathrm{MHz}$

${ }^{\mathrm{b}}$ Cumulative data represent the regulatory exposure limit per base station. Flanders has an extra limitation per antenna for indoor places and children's and school playgrounds: $10.6 \mathrm{~mW} / \mathrm{m}^{2}$ between 10 and $400 \mathrm{MHz}, 0.027 * \mathrm{fmW} / \mathrm{m}^{2}$ between 400 and $2000 \mathrm{MHz}, 53.2 \mathrm{~mW} / \mathrm{m}^{2}$ between 2 and $10 \mathrm{GHz}$.

${ }^{\mathrm{c}}$ In both legislations, there is also a cumulative limit across frequencies for all sources: $\sum S_{i} / S_{\text {limit, } i} \leq 1$ with $\mathrm{S}_{\mathrm{i}}\left(\mathrm{mW} / \mathrm{m}^{2}\right)$ the measured power density at frequency i and $\mathrm{S}_{\text {limit,i }}\left(\mathrm{mW} / \mathrm{m}^{2}\right)$ the limit value (as shown in the table above) at that frequency.

All five microenvironments in each city were measured in a single day. The measurement days were chosen as close as possible to each other in order to limit the temporal effects between different days. All measurements were performed between 9:00 and 17:00. Measurements were performed at a fixed time for each microenvironment across all cities during October November 2017. These times were changed for the second measurement campaign in order to limit influences of temporal variability (Bhatt, et al., 2016a,b).

For the measurements during October - November 2017, in each area, a path of about $1.5 \mathrm{~km}$ was defined. This path was repeated twice. This amounted to a measurement time of about 3035 min (Bhatt et al., 2016a,b) per microenvironment. With a sampling interval on the ExpoMRF of $15 \mathrm{~s}$, this lead to about 120-140 samples. The measurements in the railway station were executed in the corridors and not on the platforms.

In the train station, industrial area and shopping street of every city, the same path was used during February - March 2018. This path was again repeated twice. The measurement paths in the residential and the park and recreation areas were slightly altered during February - March 2018: they were twice as long but only travelled once. These adaptations were made prior to the data analysis of the measurements during October - November 2017. Repeatability was evaluated by comparing the measurements during October - November 2017 to those during February - March 2018.

\subsubsection{Temporal measurements}

To measure temporal variability of RF-EMF exposure, three of the previously mentioned cities were considered: Bruges, Brussels, and Ghent. The studied locations are listed in Table B3 of Appendix B. In each of these cities two new microenvironments (industrial and residential) 
were selected. In each of these six microenvironments we selected a path of about $2 \mathrm{~km}$ length which takes about 20-25 min to measure. A seventh microenvironment was added: the shopping area in Bruges from the spatial measurements, because a high temporal variation was expected in this microenvironment. Here, measurements were conducted along the same path of about $1.5 \mathrm{~km}$, which took about 15-20 min. The sample interval of the ExpoM-RF was set to $3 \mathrm{~s}$, which amounted to approximately $400-500$ samples for the $2 \mathrm{~km}$ paths and about 300 400 samples for the $1.5 \mathrm{~km}$ path in the shopping area in Bruges.

To facilitate the analysis, we divided the workday in different timeslots (Figure 2): Rush, defined between 7:00 and 9:15 in the morning and 16:30 and 19:00 in the evening, is characterised by a lot of traffic of people going to and back from work. Non-rush, defined between 9:15 in the morning and 16:30 in the afternoon, characterised as the time when most people are at work. Night, defined between 22:00 in the evening and 6:00 in the morning, characterised as the time when most people are asleep.

Figure 2: Overview of the used timeslots on weekdays.

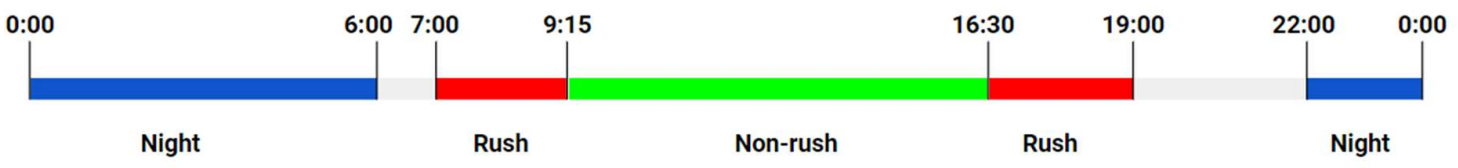

In the first two measurement periods (October - November 2017 and February - March 2018) one measurement was performed during both rush and non-rush timeslots in all of the six microenvironments. During February - March 2018, the measurements during the rush and non-rush timeslots in Bruges were repeated twice, along the same path and in the same week, but on different days. In the residential and industrial area in Brussels and the residential area in Ghent two crossing paths per area were defined (Thielens et al., 2018). These paths were both about $2 \mathrm{~km}$ long. During October - November 2017 all measurements were conducted along path 1, whilst during February-March 2018, all measurements were performed along path 2. As there were two rush timeslots to be measured (shown in Figure 2), rush hour measurements in Brussels were performed in the morning, while in Ghent and Bruges this was done in the evening. Measurements in the Night timeslot were conducted in the residential and industrial area in Brussels and Bruges, in the period October - November 2017.

The shopping area in Bruges was measured seven times (start times were: 8:15, 14:30, 16:00, 17:00, 18:00, 19:15 and 23:00) on a single Saturday during the first measurement period. Measurements were repeated in the second measurement period. This was done on two weekdays at 17:00 and on a Saturday at 8:15 and 17:00. This enabled a comparison of exposure on a Saturday to exposure on a weekday and allowed to compare variations within the Saturdays to variations between the Saturdays.

During the third measurement campaign (January $14^{\text {th }}-19^{\text {th }} 2019$ ) the representativeness of each path for its respective microenvironment was tested. This was done by measuring along two crossing paths. In Brussels and in the residential area in Ghent, the already defined paths were used, whilst in the other microenvironments we now defined a second path as well. In 
Ghent, an eighth microenvironment was defined in a residential area containing a train station. In each microenvironment both paths were measured once, back to back, during non-rush hours, but were not considered in the rush versus non-rush comparison. The microenvironments that were measured in all three campaigns were studied to determine whether any long term evolutions had occurred from November 2017 to January 2016.

Lastly, measurements were conducted during train rides in the last measurement campaign along two trajectories: between Bruges and Ghent and between Ghent and Brussels. These measurements were categorised into rush and non-rush based on how many people were in the same waggon as the researcher ( $>20$ : rush, $<20$ : non-rush).

\subsection{Data processing and Statistical analysis}

The ExpoM-RF measures the electric field strength $\mathrm{E}$ in $\mathrm{V} / \mathrm{m}$ in 16 frequency bands. They are listed in Table A1. In this study, there was no data recorded above the upper LOD. Data recorded below the lower LOD (LLOD), or censored data, was substituted by $\frac{L L O D}{\sqrt{2}}$ (Ganser \& Hewett, 2010; Thielens et al., 2018). The frequency bands were grouped in the following categories: downlink (Mobile 800, Mobile 900, Mobile 1800, Mobile 2100 and Mobile 2600), uplink (Mobile 800, Mobile 900, Mobile 1800, Mobile 2100 and Mobile 2600), broadcast (FM and TV), other (DECT, Wifi 2G, Mobile 3500 and Wifi 5000) and total (all bands). Grouping was done as in the following example for downlink:

$$
\begin{gathered}
E_{\text {downlink }}^{2}=E_{\text {mobile800downlink }}^{2}+E_{\text {mobile } 900 \text { downlink }}^{2}+E_{\text {mobile1800downlink }}^{2} \\
+E_{\text {mobile2100downlink }}^{2}+E_{\text {mobile2600downlink }}^{2}
\end{gathered}
$$

For this study, exposure was expressed in terms of the electromagnetic power density $\mathrm{S}\left(\mathrm{W} / \mathrm{m}^{2}\right)$. The relation with the electric field is: $S=E^{2} / 377$. As summary statistics, we obtained the arithmetic mean and standard deviation, and the $16^{\text {th }}, 50^{\text {th }}, 84^{\text {th }}$, and $95^{\text {th }}$ percentiles.

To compare median exposure in different microenvironments, cities, timeslots, and measurement campaigns, Wilcoxon Rank Sum (WRS) tests were performed. For all WRS tests, a significance level of $\mathrm{p}<0.05$ (one-sided) was used.

To compare the cities in terms of overall exposure, we created a pool of data per city from all microenvironments and obtained the summary statistics from those pools. Every pool consisted of an equal amount of data from each microenvironment. This was obtained by taking the number of datapoints $n$ from the microenvironment with the smallest dataset, and taking $n$ samples from the datasets of the other microenvironments. We repeated this a 100 times and obtained the summary statistics from each of those pools. The reported values are the arithmetic averages of those 100 summary statistics.

Repeatability of the measurements was tested using the Spearman correlation between the summary statistics of the first and the second repetition of the same path measured on the same day during the spatial measurements (Section 2.2.1). 
The crossing paths defined in the same microenvironments for the temporal measurements (Section 2.2.2.) were used to test the representativeness of a path for the considered microenvironment. To this aim the Spearman correlation coefficient between the summary statistics of the pooled data of path 1 and the pooled data of path 2 was calculated.

\subsection{Device calibration}

Both researchers carried the device close to the body. During the spatial measurements this was in a jacket pocket, while during the temporal measurements this was in a backpack. In both cases a calibration of the ExpoM-RF was performed for 13 out of the 16 bands (Table C1), following the same procedures as adopted by Thielens et al. (2015). The calibration was performed in an anechoic chamber, with the researcher on whom the ExpoM-RF was calibrated standing on a rotational platform on one side of the chamber, and a transmitting antenna $\left(\mathrm{T}_{\mathrm{X}}\right)$ on the other. For each frequency band the $T_{X}$ transmits at a constant output power at the centre frequency of the band (Table C2). Data measured by the ExpoM-RF on the body of the researchers was then compared to data measured in free-space in order to obtain a calibration factor. The calibration procedure and the calculation of the calibration factors are further explained in Appendix C.

\section{Results}

\subsection{Spatial analysis}

\subsubsection{Descriptive statistics}

Table 2 lists the proportions of non-detects, values falling below the LODs, during the spatial measurements. The percentages were calculated taking into account all measured data that were used to calculate summary statistics shown in Figure 3 and Table D2 (Appendix D). Proportions of non-detects range from $0.1 \%(900 \mathrm{DL})$ up to $99 \%$ for WiMax $3.5 \mathrm{GHz}$ and 2600 UL, which are both technologies that were not in use at the time of measurements. No data above the upper LOD were measured.

Table D2 shows the summary statistics per microenvironment for each of the studied quantities. The area with the highest average total exposure $\left(7.83 \mathrm{~mW} / \mathrm{m}^{2}\right)$ was the Park and Recreation area in Brussels. The lowest average exposure $\left(0.05 \mathrm{~mW} / \mathrm{m}^{2}\right)$ was found in the Train Station in Bruges, an indoor area. The lowest average exposure in outside areas was found in the Park and Recreation area in Bruges $\left(0.13 \mathrm{~mW} / \mathrm{m}^{2}\right)$. Downlink and broadcasting were the most important sources of exposure. Downlink was dominant in all industrial areas, except for the one in Hasselt, in all railway stations, and all shopping streets, except for the one in Antwerp. On the contrary, broadcasting was dominant in all park and recreation areas. Downlink was dominant in three of the five residential areas (Bruges, Hasselt and Antwerp) with broadcasting dominating the other two (Brussels and Ghent). Figure 3 shows the measured power density $\mathrm{S}$ per microenvironment, with the relative contribution of each of the studied exposure quantities. 
Table 2: Percentage of censored data per frequency band during the spatial analysis.

\begin{tabular}{lc}
\hline Service & $\begin{array}{c}\text { Percentage of } \\
\text { Measurements } \\
\text { underneath lower } \\
\text { LOD (\%) }\end{array}$ \\
\hline FM Radio & 14 \\
DVB-T & 4.9 \\
800 DL & 2.8 \\
800 UL & 88 \\
900 UL & 88 \\
900 DL & 0.1 \\
1800 UL & 75 \\
1800 DL & 1.2 \\
DECT & 8.1 \\
2100 UL & 89 \\
2100 DL & 0.9 \\
Wifi 2G & 47 \\
2600 UL & 99.6 \\
2600 DL & 51 \\
WiMax 3.5 & 99 \\
Wifi-5G & 86 \\
\hline
\end{tabular}

Figure 3: Arithmetic average of measured $S$ in all frequency bands in the 25 studied microenvironments in Flanders and the Brussels Capital Region. The height of the bars indicates the total average $S$, while the different subdivisions of the bars indicate the relative contributions of $D L$, $U L$, broadcast, and other signals. The standard deviations of the shown averages can be found in Table D2.

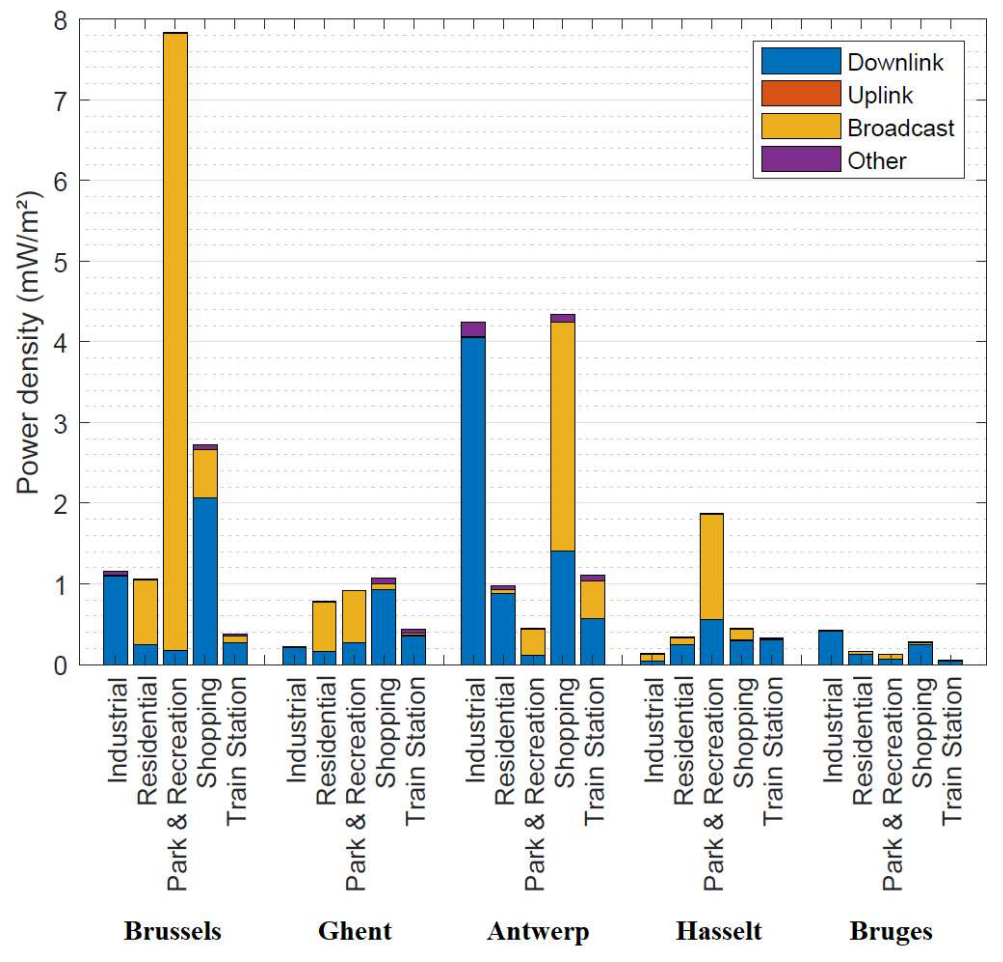




\subsubsection{Comparison of cities and investigation of the impact of regulatory limits on RF-EMF exposure}

Table 3 shows a comparison between measured power densities in the five studied cities. The results shown in Table 3 were obtained from pooling an equal amount of data points from every microenvironment in each city. The highest average total power density was measured in Brussels, mainly caused by a relatively high broadcast component. The lowest average total power density was measured in Bruges. The average downlink exposure was the highest in Antwerp (see also discussion Section 4.1.2.).

\subsubsection{Repeatability of the measurements}

Figure 4 shows scatterplots of the median measured $S$ in each of the 25 studied microenvironments from two different measurement days (November and February). The Spearman's correlation is shown alongside the measured data points. Correlations were found to be high $(r>0.89)$ for median $\mathrm{S}$ for any of the considered exposure quantities. This indicates a good repeatability for the used measurement protocol.

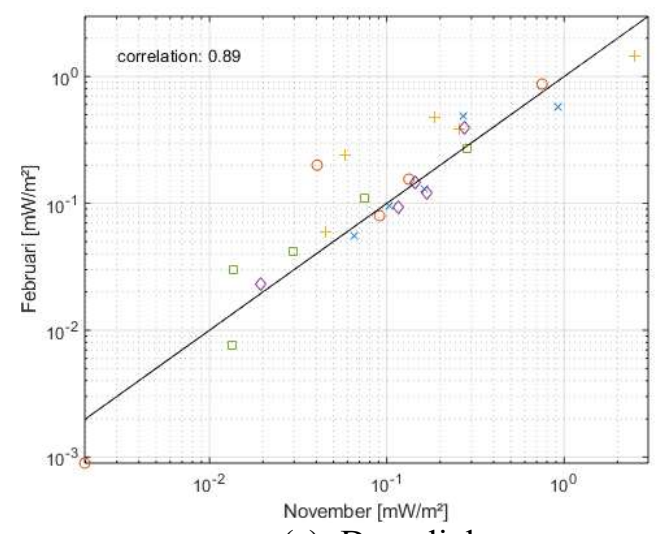

(a) Downlink

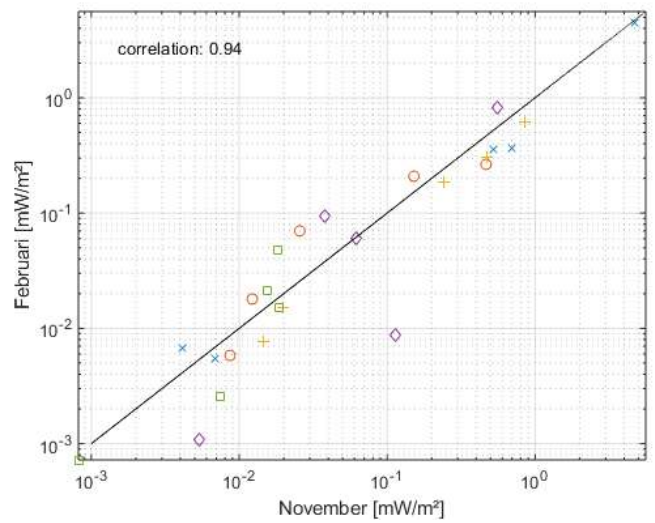

(c) Broadcast

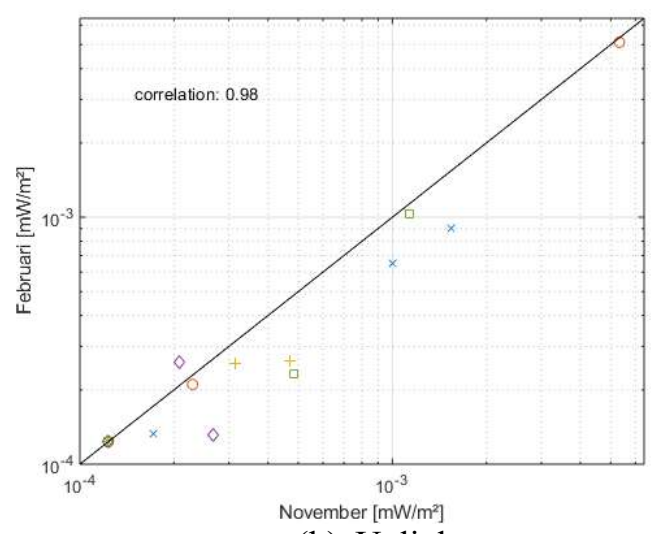

(b) Uplink

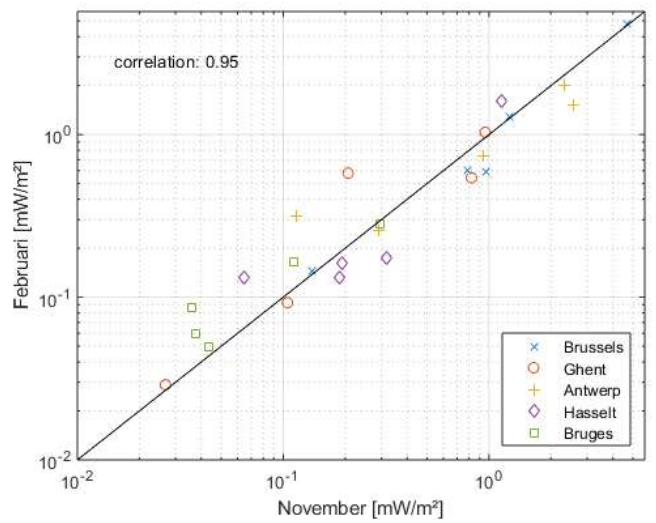

(d) Total

Figure 4: Median values of the total exposure measured along the same path in November versus in February, on a logarithmic scale. 
Table 3: Summary statistics of $S$ measurements using the ExpoM-RF in five cities in the Flemish Region and the Brussels Capital Region. The $S$ shown are averages in each city with every microenvironment represented equally.

\begin{tabular}{|c|c|c|c|c|c|c|c|c|c|c|c|c|c|c|c|c|c|c|c|c|c|c|c|c|c|c|c|c|c|c|}
\hline \multirow[t]{2}{*}{$\mathbf{S}^{\mathbf{a}}\left(\mathbf{m W} / \mathbf{m}^{2}\right)$} & \multicolumn{6}{|c|}{ DL } & \multicolumn{6}{|c|}{$\mathbf{U L}$} & \multicolumn{6}{|c|}{ Broadcast } & \multicolumn{6}{|c|}{ Others } & \multicolumn{6}{|c|}{ Total } \\
\hline & $\mu$ & std & $p_{16}$ & $p_{50}$ & $p_{84}$ & $p_{95}$ & $\mu$ & std & $p_{16}$ & $p_{50}$ & $p_{84}$ & $p_{95}$ & $\mu$ & std & $p_{16}$ & $p_{50}$ & $p_{84}$ & $p_{95}$ & $\mu$ & std & $p_{16}$ & $p_{50}$ & $p_{84}$ & $p_{95}$ & $\mu$ & std & $p_{16}$ & $p_{50}$ & $p_{84}$ & $p_{95}$ \\
\hline \multicolumn{31}{|l|}{ City } \\
\hline Brussels & 0.77 & 2.22 & 0.03 & 0.20 & 1.04 & 3.38 & $1 e-3$ & $4 e-3$ & $1 \mathrm{e}-4$ & $2 \mathrm{e}-4$ & $1 \mathrm{e}-3$ & 0.01 & 1.83 & 5.59 & 0.01 & 0.27 & 2.72 & 8.88 & 0.03 & 0.09 & $4 \mathrm{e}-3$ & 0.01 & 0.04 & 0.09 & 2.63 & 5.88 & 0.20 & 0.91 & 4.31 & 9.55 \\
\hline Ghent & 0.39 & 1.04 & $2 \mathrm{e}-3$ & 0.10 & 0.68 & 1.46 & $3 e-3$ & $1 \mathrm{e}-2$ & $1 e-4$ & 1e-4 & $3 e-3$ & 0.01 & 0.27 & 0.67 & 0.01 & 0.04 & 0.38 & 1.29 & 0.03 & 0.13 & $4 e-3$ & 0.01 & 0.02 & 0.15 & 0.69 & 1.33 & 0.04 & 0.26 & 1.21 & 2.38 \\
\hline Antwerp & 1.35 & 3.80 & 0.03 & 0.25 & 1.86 & 5.68 & $7 e-4$ & $4 \mathrm{e}-3$ & $1 e-4$ & 1e-4 & $5 e-4$ & $2 e-3$ & 0.73 & 2.77 & 0.01 & 0.15 & 0.82 & 1.86 & 0.08 & 0.22 & $5 e-3$ & 0.01 & 0.11 & 0.34 & 2.15 & 4.73 & 0.14 & 0.68 & 3.33 & 9.05 \\
\hline Hasselt & 0.29 & 0.54 & 0.02 & 0.12 & 0.44 & 1.35 & $5 e-4$ & $3 e-3$ & $1 e-4$ & $1 \mathrm{e}-4$ & $4 \mathrm{e}-4$ & $1 e-3$ & 0.33 & 0.87 & $3 e-3$ & 0.05 & 0.36 & 1.88 & 0.01 & 0.03 & $4 e-3$ & 0.01 & 0.01 & 0.03 & 0.63 & 1.08 & 0.06 & 0.19 & 1.09 & 2.90 \\
\hline Bruges & 0.18 & 0.38 & 0.01 & 0.04 & 0.28 & 0.76 & $1 e-3$ & $8 \mathrm{e}-3$ & $1 e-4$ & 1e-4 & $9 e-4$ & $4 e-3$ & 0.03 & 0.05 & $1 e-3$ & 0.01 & 0.04 & 0.10 & 0.01 & 0.01 & $4 e-3$ & $4 e-3$ & 0.01 & 0.02 & 0.21 & 0.39 & 0.03 & 0.07 & 0.34 & 0.80 \\
\hline
\end{tabular}


In Table 4, we provided the Spearman's correlation coefficient for the other summary statistics. All coefficients have a p-value smaller than 0.01 . We found the highest correlations for the median values. This indicates repeatability of investigating these statistics over a route.

Table 4: Spearman's correlation coefficient ( $r$ ) between the following summary statistics: arithmetic mean $(\mu), 16^{\text {th }}, 50^{\text {th }}, 84^{\text {th }}$, and $95^{\text {th }}$ percentile of measured $S$ in 25 microenvironments spread over five different cities.

\begin{tabular}{c|c|c|c|c|c}
\hline $\mathrm{r}(\mathrm{p})$ & $\boldsymbol{\mu}$ & $\boldsymbol{p}_{\mathbf{1 6}}$ & $\boldsymbol{p}_{\mathbf{5 0}}$ & $\boldsymbol{p}_{\mathbf{8 4}}$ & $\boldsymbol{p}_{\mathbf{9 5}}$ \\
\hline $\mathrm{DL}$ & 0.70 & 0.74 & 0.89 & 0.84 & 0.52 \\
UL & 0.74 & 0.84 & 0.96 & 0.92 & 0.85 \\
Broadcast & 0.88 & 0.90 & 0.94 & 0.91 & 0.89 \\
Others & 0.62 & 0.63 & 0.81 & 0.76 & 0.60 \\
Total & 0.78 & 0.89 & 0.95 & 0.90 & 0.62 \\
\hline
\end{tabular}

\subsection{Temporal analysis}

\subsubsection{Descriptive statistics}

Table 5 lists the percentages of non-detects during the temporal measurements. The data was split between measurements while walking and measurements on a train. This separation of data was motivated by the differences in the uplink and broadcast bands during train rides. During the outdoor measurements on foot, uplink (disregarding 2600 UL which was not in use at the time of study) was found to lead to high percentages of non-detects ( $85-94 \%$ censored data), in contrast to measurements during the train rides where for 800 UL only $4 \%$ of the data were censored and values were close to $40 \%$ for $900 \mathrm{UL}$ and 1800 UL. $2100 \mathrm{UL}$ was only $65 \%$ censored during train measurements, in contrast to $94 \%$ during measurements while walking. FM Radio and DVB-T showed opposite behaviour with low percentages of censored data: $8 \%$ and $7 \%$, respectively during the measurements on foot and higher percentages of censored data: $77 \%$ and $37 \%$, respectively, during the train rides. In both cases, 2600 UL ( $99-92 \%$ censored

Table 5: Percentages of censored data per frequency band during the temporal measurements.

\begin{tabular}{lcc}
\hline Service & $\begin{array}{c}\text { Percentage of } \\
\text { Measurements } \\
\text { underneath lower } \\
\text { LOD while } \\
\text { walking (\%) }\end{array}$ & $\begin{array}{c}\text { Percentage of } \\
\text { Measurements } \\
\text { underneath lower } \\
\text { LOD on a train } \\
\text { (\%) }\end{array}$ \\
\hline FM Radio & 8.2 & 77 \\
DVB-T & 7.0 & 37 \\
800 DL & 0.5 & 0.0 \\
800 UL & 85 & 3.6 \\
900 UL & 93 & 41 \\
900 DL & 0.3 & 0.7 \\
1800 UL & 88 & 44 \\
1800 DL & 0.7 & 44 \\
DECT & 2.2 & 71 \\
2100 UL & 94 & 65 \\
2100 DL & 0.4 & 41 \\
Wifi 2G & 40 & 51 \\
2600 UL & 99.0 & 92 \\
2600 DL & 65 & 85 \\
WiMax 3.5 & 93 & 99 \\
Wifi-5G & 88 & 99.9 \\
\hline
\end{tabular}


data) and WiMax 3.5 (93-99\%) showed high percentages of non-detects. For measurements on a train, Wifi-5G (99.9\%) was almost entirely censored.

Table D1 (Appendix D) shows the summary statistics per timeslot in Bruges, Brussels, Ghent, and during train rides in between those cities. The timeslot with the highest measured average exposure in the outdoor case $\left(1.24 \mathrm{~mW} / \mathrm{m}^{2}\right)$ was night time in Bruges. During train rides this was during rush $\left(2.16 \mathrm{~mW} / \mathrm{m}^{2}\right)$. The lowest average exposure $\left(0.18 \mathrm{~mW} / \mathrm{m}^{2}\right)$ for the outdoor case was during non-rush hours in Ghent, and also during non-rush hours in a train $(0.21$ $\mathrm{mW} / \mathrm{m}^{2}$ ). In both Brussels and Bruges, mean exposures at night were higher than during the day. However, in Bruges, median exposure was highest during rush hours. The measurements on a Saturday in Bruges were all from the shopping area, while measurements during rush, non-rush and nightly hours were from the industrial and residential area.

Downlink was dominant during all measurements while walking, and uplink was dominant during all measurements in a train. Upon further analysis of the data measured during rush hours on train rides, we found that the exposure during one of the four rides was much higher (mean total exposure of $7.10 \mathrm{~mW} / \mathrm{m}^{2}$ ) than the other three (combined mean total exposure of $0.44 \mathrm{~mW} / \mathrm{m}^{2}$ ), with every train measurement having about the same number of samples. So while the mean of these three rush measurements was still higher than the non-rush measurements, the high difference between rush and non-rush measurements was mainly caused by one measurement. Interestingly, the median exposure was only about $25 \%$ lower during non-rush compared to rush, while the mean exposure was $90 \%$ lower during non-rush compared to rush. We could not find a correlation between number of people and exposure during train rides.

The mean $\mathrm{S}$ is shown visually in Figure 5 per timeslot in each city and during train rides, with the relative contribution of each of the studied exposure quantities. Mean exposure was higher during rush in Ghent, Brussels and on a train, while it was higher during non-rush in Bruges.

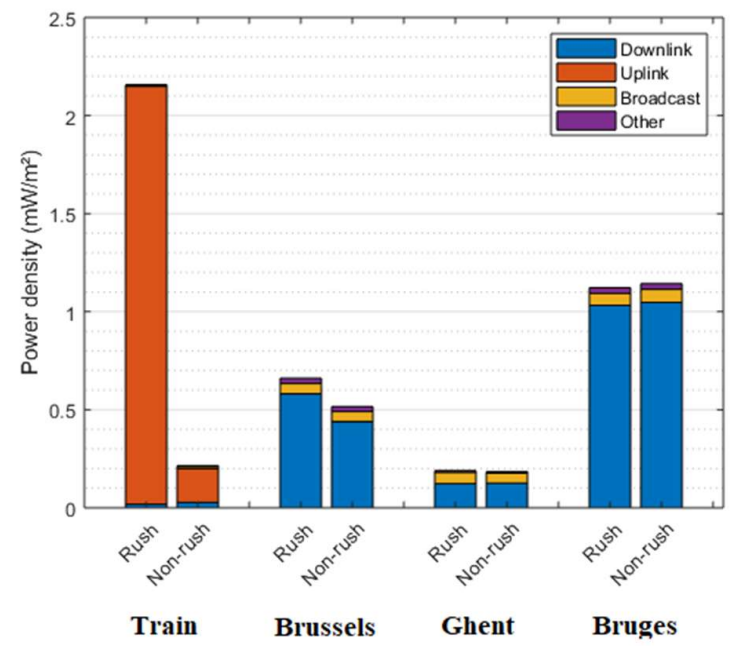

Figure 5: Arithmetic average measured $S$ in all frequency bands in the three cities and on a train. 


\subsubsection{Temporal evolution of exposure in industrial and residential areas.}

The overall exposure during rush hours was found to be significantly higher than during nonrush hours after performing the one-sided WRS test on the pool of the 13 rush - non rush pairs of measurements. This was also the case for all data from Brussels. In Ghent and Bruges, the difference in total exposure was not significant. In Ghent however, downlink exposure was significantly higher during non-rush hours. In each of the three cities, uplink was significantly higher during non-rush hours. For train rides, exposure during rush was significantly higher than during non-rush.

Total exposure was found to be significantly higher at night compared to during the day in both Brussels and Bruges due to downlink sources. In contrast, uplink exposure was significantly lower at night in Brussels and in the overall pool of both cities. In Bruges, the difference for uplink was not significant. In further analysis, we found that the elevation in downlink exposure only occurred in industrial areas. In residential areas, we observed no significant difference between total exposure during day and night.

To assess long term evolutions, data measured during each of the three measurement campaigns were pairwise compared for each of the microenvironments. For uplink, we found a systematic rise over time. For the other groups of frequency bands, this was not the case: although significant differences were found, these were not consistent across the different microenvironments.

\subsubsection{Temporal evolution of exposure in a shopping area}

Figure 6 shows boxplots for downlink, uplink, broadcasting and total exposure of each repetition in the shopping area in Bruges on a Saturday. Repetitions were done at 8:15, 14:30, 16:00, 17:00, 18:00, 19:15 and 23:00. The exposure from downlink sources was the highest at 8:15 and 23:00, whilst the exposure from uplink sources was the highest at 14:30 and 16:00.

\subsubsection{Representativeness of the measured paths}

Figure 7 shows scatterplots of the median power density $\mathrm{S}$ measured along different paths in three microenvironments. The Spearman's correlation is shown as well.

Table 6 shows Spearman's correlation coefficient for each of the summary statistics in all groups of frequency bands. For downlink, broadcast and total exposure the p-values were all below 0.05 except for the $95^{\text {th }}$ percentile of downlink. This indicates a good representativeness of the selected paths for their respective microenvironments. For uplink and other technologies, this conclusion cannot be made as almost all p-values were above the significance level of 0.05 (except for the median of others). 


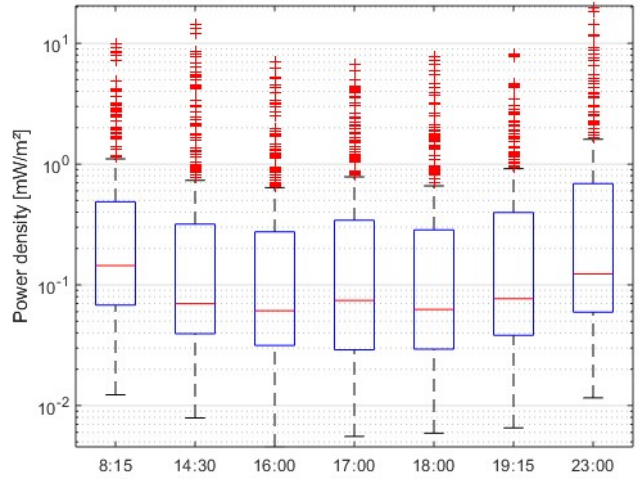

(a) Downlink

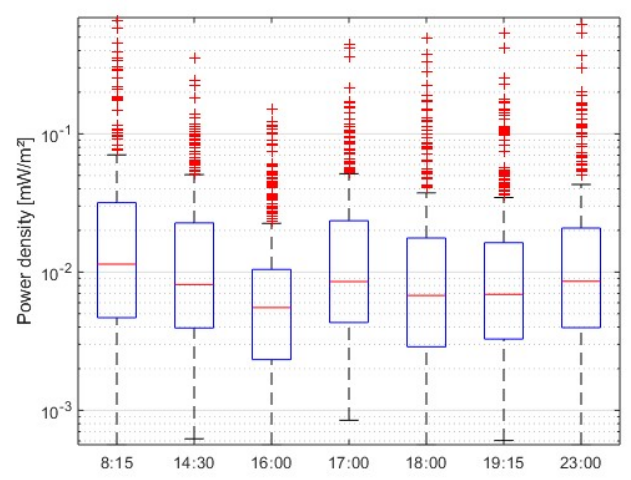

(c) Broadcast

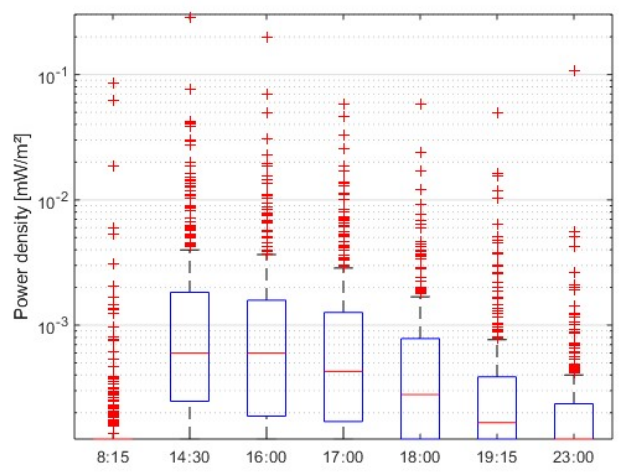

(b) Uplink

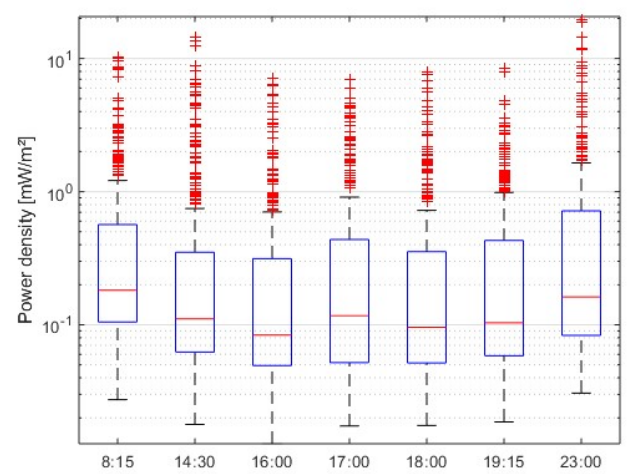

(d) Total

Figure 6: Boxplots on a logarithmic scale per group of frequency bands of the repeated measurements in the Shopping area in Bruges. The x-axis indicates the time of measurement. Red lines indicate the median values, blue boxes indicate the interquartile range (iqr, with $Q 1=p_{25}$ and $\left.Q 3=p_{75}\right)$, black whiskers indicate the outermost values that are within $(Q 1$ $1.5 *$ iqr $)$ and $(Q 3+1.5 *$ iqr $)$, the red markers indicate outliers.

Table 6: Spearman's correlation coefficient ( $r$ ) and its p-value (p) between the following summary statistics: arithmetic mean $(\mu), 16^{\text {th }}, 50^{\text {th }}, 84^{\text {th }}$, and $95^{\text {th }}$ percentile of measured $S$ in eight microenvironments spread over three different cities.

\begin{tabular}{c|cc|cc|cc|cc|cc}
\hline \multirow{2}{*}{$\mathrm{r}(\mathrm{p})$} & \multicolumn{2}{|c|}{$\boldsymbol{\mu}$} & \multicolumn{2}{|c|}{$\boldsymbol{p}_{\mathbf{1 6}}$} & \multicolumn{2}{c|}{$\boldsymbol{p}_{\mathbf{5 0}}$} & \multicolumn{2}{c|}{$\boldsymbol{p}_{\mathbf{8 4}}$} & \multicolumn{2}{c}{$\boldsymbol{p}_{\mathbf{9 5}}$} \\
\cline { 2 - 11 } & $\mathrm{r}$ & $\mathrm{p}$ & $\mathrm{r}$ & $\mathrm{p}$ & $\mathrm{r}$ & $\mathrm{p}$ & $\mathrm{r}$ & $\mathrm{p}$ & $\mathrm{r}$ & $\mathrm{p}$ \\
\hline DL & 0.79 & 0.03 & 0.88 & 0.01 & 0.90 & 0.00 & 0.76 & 0.04 & 0.71 & 0.06 \\
UL & 0.45 & 0.27 & 1.00 & 0.25 & 0.49 & 0.23 & 0.51 & 0.21 & 0.36 & 0.39 \\
Broadcast & 0.79 & 0.03 & 0.93 & 0.00 & 0.83 & 0.02 & 0.81 & 0.02 & 0.74 & 0.05 \\
Others & 0.52 & 0.20 & 0.67 & 0.08 & 0.88 & 0.01 & 0.67 & 0.08 & 0.52 & 0.20 \\
Total & 0.83 & 0.02 & 0.81 & 0.02 & 0.88 & 0.01 & 0.74 & 0.05 & 0.74 & 0.05 \\
\hline
\end{tabular}




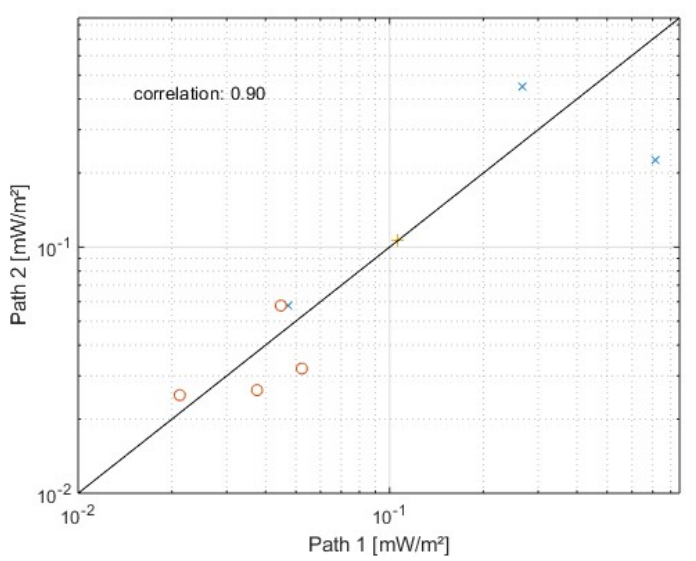

(a) Downlink

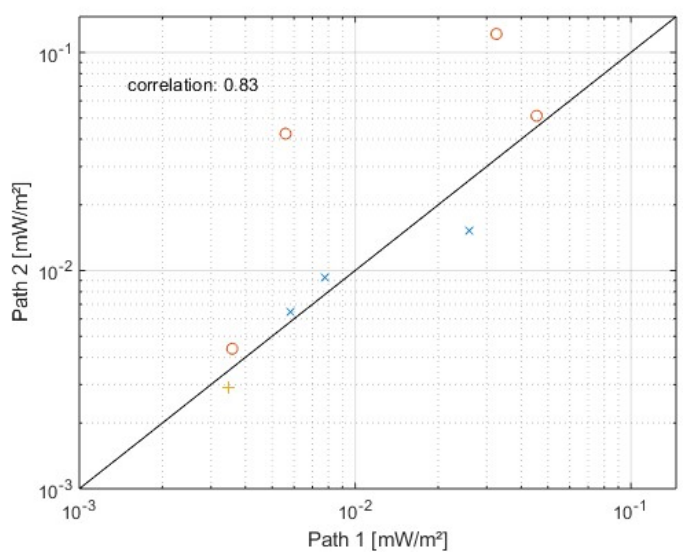

(c) Broadcast

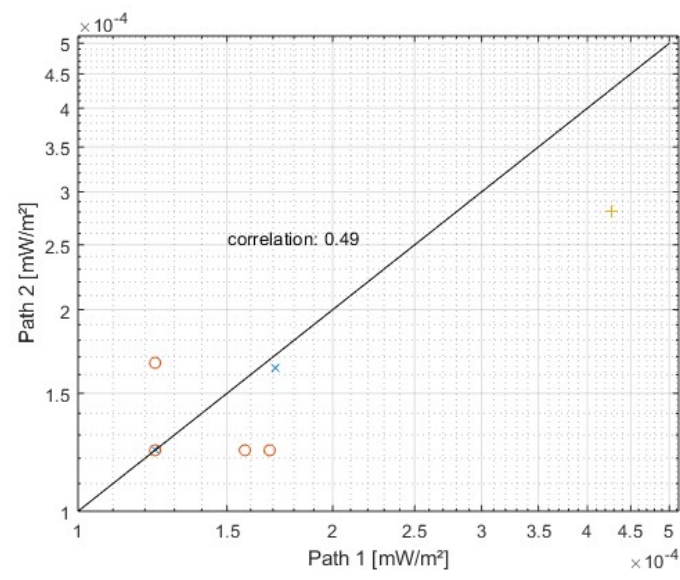

(b) Uplink*

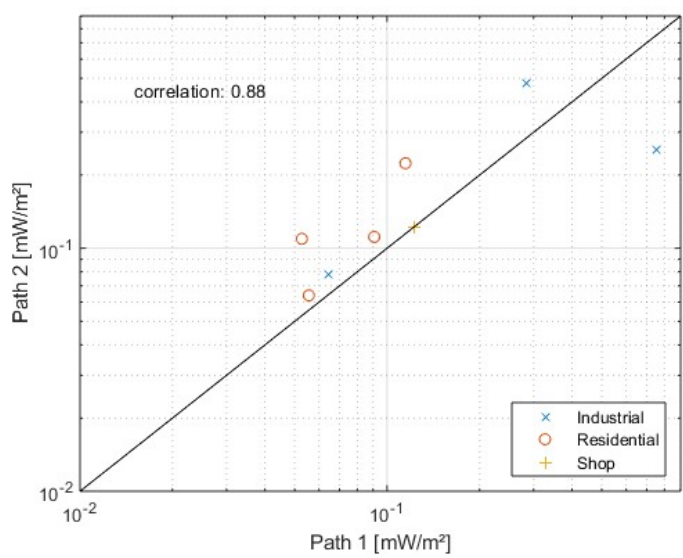

(d) Total

Figure 7: The markers show median values of downlink (a), uplink (b), broadcasting (c) and total (d) exposure measured along two different paths during the same timeslot in the same microenvironments. The Spearman correlation is also shown.

*Remark: From the five markers in the bottom left corner, the median value of at least one of the measured paths was a substituted value since more than $50 \%$ of the data was below the lower LOD of the ExpoM-RF. For the two markers on the bisector, this was the case for both measured paths.

\subsection{On-body calibration}

Measurements of incident electric field strengths were performed in free-space, using an isotropic field probe, and on the researchers' bodies using the ExpoM-RF on the same on-body locations as during the microenvironmental measurements. The results of the free-space measurements are shown in Table $\mathrm{C} 1$. These were compared to the on-body measured values in order to calibrate the measurement devices on the body in Appendix $\mathrm{C}$. We found that the body-worn devices underestimated exposure in more than $50 \%$ of the exposure situations for 10 out of 13 bands for researcher 1 and 12 out of 13 bands for researcher 2. This underestimation of personal exposure by body-worn devices has previously been shown in literature (Bhatt et al., 2016a, 2016b; Bolte \& Eikelboom 2012; Bolte 2016; Thielens et al., 2015; Aminzadeh et al., 2016). Our results are in line with those previous studies. For both 
researchers, the $900 \mathrm{MHz}$ uplink band resulted in the lowest response (5.07 and $4.73 \mathrm{~dB}$ of underestimation respectively) and the Wifi-5GHz band in the highest response (7.86 and $4.53 \mathrm{~dB}$ of overestimation respectively). Note the asymmetric distribution of each of the responses: $p_{16}$ was always further from $p_{50}$ than $p_{84}$. Aminzadeh et al. (2016) and Thielens et al. (2015) found this as well.

\section{Discussion}

For the first time, i) we conducted personal RF-EMF measurements in five of the largest cities in the Flemish and Brussels Capital Region; and ii) we assessed temporal variability during nightly hours and weekend days. This is one of a few studies where the used device (the ExpoM-RF) was calibrated on the body of the researchers. Furthermore the study design was shown to be representative and repeatable.

\subsection{Spatial analysis}

\subsubsection{Spatial variability}

One of the studied hypotheses was that higher population densities lead to higher exposure values. The evaluation of the measurements was in line with this hypothesis. The order of cities in terms of highest population density (Brussels, Antwerp, Ghent, Bruges, and Hasselt respectively) from Table B1 was almost completely followed by the order of cities in terms of highest mean and median total exposure (Table 6). Hasselt was an exception on this trend by surpassing Bruges in terms of total exposure. Furthermore, note that although the difference in population density between Ghent and Hasselt was relatively large (54\% relative difference in terms of population density), the difference in exposure values was limited ( $9 \%$ relative difference in terms of average total power density). The measurements presented in Bhatt et al. (2016a, 2016b) suggest increased levels of RF exposure in more urban environments (higher number of users) in Belgium and Australia. Thielens et al. (2018) found a similar trend in Australia. Sagar et al. (2018) found higher exposure values in central residential areas versus non-central residential areas and higher exposure values in city centers versus rural centers in a world-wide RF exposure study. Sagar et al. (2016) found similar results in Switzerland, with the exception of industrial areas. We also observed an increase of measured power density in more populated areas in our study.

Bhatt et al. (2016a) executed microenvironmental measurements in Ghent, using an on-body calibrated exposimeter and found mean total exposure of $2.1 \mathrm{~mW} / \mathrm{m}^{2}, 2.3 \mathrm{~mW} / \mathrm{m}^{2}$, and $3.6 \mathrm{~mW} / \mathrm{m}^{2}$ in residential urban, urban park, and city centre (corresponding to our shopping area) microenvironments, in Ghent, respectively. We measured $0.79 \mathrm{~mW} / \mathrm{m}^{2}, 0.92 \mathrm{~mW} / \mathrm{m}^{2}$, and $1.07 \mathrm{~mW} / \mathrm{m}^{2}$ (Table D2) in the corresponding microenvironments. These values are lower because we did not apply a correction factor to account for body-induced underestimation directly, in contrast to Bhatt et al. (2016a). We characterize this underestimation in Section 4.3 and in Appendix C. Urbinello et al. (2014b) executed measurements in both Ghent and Brussels and reported mean total exposures averaged over all areas of $0.27 \mathrm{~mW} / \mathrm{m}^{2}$ and $0.45 \mathrm{~mW} / \mathrm{m}^{2}$, in Ghent and Brussels, respectively. We found higher values of $0.69 \mathrm{~mW} / \mathrm{m}^{2}$ and $2.6 \mathrm{~W} / \mathrm{m}^{2}$ (Table 
D2). Urbinello et al. (2014b) measured average downlink values of $0.32 \mathrm{~mW} / \mathrm{m}^{2}$ and 0.19 $\mathrm{mW} / \mathrm{m}^{2}$ and average uplink values of $0.08 \mathrm{~mW} / \mathrm{m}^{2}$ and $0.01 \mathrm{~mW} / \mathrm{m}^{2}$ for Brussels and Ghent, respectively. We measured downlink values that were almost twice as high: $0.77 \mathrm{~mW} / \mathrm{m}^{2}$ and $0.39 \mathrm{~mW} / \mathrm{m}^{2}$, while our measured uplink values were lower: $0.001 \mathrm{~mW} / \mathrm{m}^{2}$ and $0.003 \mathrm{~mW} / \mathrm{m}^{2}$ (Table D2). These measurements suggest that the downlink exposure in Belgium has increased over time, due to better coverage, which simultaneously lowered the uplink exposure, and higher use of network capacity. This was in line with previous observations in Brussels and Ghent made by Urbinello et al. (2014c), where increases over time in outdoor exposure were observed in both cities. It should be noted that an increase in measured total exposure or downlink exposure does not imply an increase in actual absorbed RF power, which is expected to scale with the self-induced uplink exposure which is not measured in this study.

We observed low percentages of censored data (from $0.1 \%$ for 900 DL to $2.8 \%$ for 800 DL) in the downlink bands (disregarding 2600 DL which was not in use at the time of study) for both spatial and temporal measurements (Table 2 and 5). This was in contrast with the uplink bands (disregarding $2600 \mathrm{UL}$ ), where the percentages of censored data range from $75 \%$ for $1800 \mathrm{UL}$ to $94 \%$ for 2100 UL during the same measurements.

Broadcast bands had relatively low percentages of censored data as well (from $4.9 \%$ for TV to $14 \%$ for FM). Since downlink and broadcasting base stations were always radiating, it was expected that in outdoor urban environments, they could be measured almost everywhere. On the other hand, Uplink is used for communication from the users back to the base stations, which typically only happens during specific activities, e.g. during phone calls. Furthermore, these devices at the users' side radiate at a much lower power than base stations, so their signal can only be measured within a shorter range in comparison to base station antennas using the same sensitivity (Thielens et al., 2018). During train rides, there was much less censored data in the uplink bands: from $3.6 \%$ in 800 UL to $65 \%$ in 2100 UL. This was observed because in a train, one is constantly in close proximity to other users, which subsequently can be expected to show more uplink activity. Moreover, UL signals are partially contained within the train due to its metallic structure. This will be further discussed in Section 4.2.1. Broadcasting and the 2100 and 1800 DL bands showed higher percentages of non-detects during train rides. This is due to two reasons: first, the train partially shields incident DL signals, second, the studied train rides were mostly through rural areas, where there were less base stations. The Mobile 2100 and 1800 DL bands have a higher path loss than their counterparts at lower frequencies (800 DL and $900 \mathrm{DL}$ ), so in rural areas $800 \mathrm{DL}$ and $900 \mathrm{DL}$ are a logical choice for providers of telecommunication networks (Thielens et al., 2018).

\subsubsection{Impact of regulatory limits on RF-EMF exposure}

By only taking the effect of population density into account, one would expect exposure to be highest in Brussels for each of the groups of frequency bands. However, for downlink, this was not the case. Downlink exposure was 75\% higher in Antwerp compared to Brussels, while the population density of Antwerp was 66\% lower than Brussels. The non-ionizing radiation legislation in the Brussels Capital Region was stricter concerning norm values than in the Flemish Region. Since downlink was typically dominating the total exposure, effects of 
legislation would be felt more for mobile communication base stations than for broadcasting base stations. Hence, it is likely that regulatory limits had an impact on downlink exposure in Brussels. Population density was still a more important factor, since the downlink exposure in Ghent, Hasselt and Bruges were still lower than the one measured in Brussels. Urbinello et al. (2014b) did not find an impact of regulatory limits when comparing four cities (Amsterdam, Basel, Brussels, and Ghent). However, they did not take into account population density. The population density in Amsterdam (5042 people $/ \mathrm{km}^{2}$ ) is 32\% lower than in Brussels, while they measured the average downlink exposure in Amsterdam to be 17\% higher than in Brussels. Since the regulatory limits were much less stringent in Amsterdam than in Brussels, one could invoke the impact of these limits.

\subsubsection{Repeatability}

The Spearman correlation coefficients found for median exposure, were between 0.81 and 0.96 (Table 4), for other and downlink respectively. The high correlation coefficients showed that the measurements were repeatable over time. Repeatability of microenvironmental studies was previously studied by Sagar et al. (2016), who found correlations $>0.51$ between arithmetic means obtained along two repeated measurements of the same path. Thielens et al. (2018) also studied repeatability and found correlations $>0.62$ for different summary statistics. These studies are in line with our findings.

\subsection{Temporal analysis}

\subsubsection{Temporal variability}

We observed that exposure during rush hours was subtly but significantly higher than during non-rush hours in Brussels (Table D1 in Appendix D). In Ghent and Bruges, differences between rush and non-rush hours were not significant. Comparing all pooled data measured during rush hours to all pooled data measured during non-rush hours, this amounts to a significantly higher exposure during rush hours. During rush hours we expected more active users, so base stations have to emit a higher power (Thielens et al., 2018). This leads to higher downlink exposure. The total exposure measured while walking was mostly due to downlink bands, since broadcast exposure was mostly constant throughout the timeslots and uplink and other bands have power densities that were over 10 times lower than the downlink exposure (Table D1). We observed exposure from uplink sources while walking to be higher during nonrush hours (Table D1). This might be due to people enjoying leisure time outside rush hours. Although during rush hours, there was more traffic outside, users were typically inside a vehicle. Thielens et al. (2018) and Urbinello et al. (2014c) observed small variances during different times of day, but did not measure outside of office hours. Bolte and Eikelboom (2012) found higher values between 18:00 and 23:00 than between 7:00 and 18:00, but did not further divide the measurements in timeslots comparable to the ones in this study. Mahfouz et al. (2012) found higher exposure between 12:00 and 14:00 and between 17:00 and 21:00, compared to between 8:00 and 12:00 and between 14:00 and 17:00. They defined these hours as rush hours for data traffic. These timeslots partly overlap with our timeslots defined as rush hours for human traffic. 
We observed higher exposure at night than during the day from downlink and broadcasting sources. In further analysis, we found that these elevations only occurred in industrial areas. A possible explanation is that during the day, traffic blocked potential lines of sight paths between the base stations and the researcher. At night, this traffic was absent, leading to higher exposure values. Bolte and Eikelboom (2012) and Frei et al. (2009) found higher values during daytime than at night. However, these were personal survey studies, so measurements at night were mainly from indoor environments, while measurements during the day were from a mixture of indoor and outdoor measurements. Exposure in urban environments is typically higher outdoors than it is indoors (Bhatt et al., 2016a). Joseph and Verloock (2010) and Aerts et al. (2018) found exposure to be lower at night than during the day using long-term spot measurements.

During train rides, the biggest source of exposure was uplink (81\% and $99 \%$ during non-rush and rush, respectively). Firstly, downlink and broadcasting exposure were lower than in the other microenvironments. This is on the one hand because a train is an indoor environment and sources for downlink and broadcasting exposure are outside, and thus attenuated after propagating to an indoor environment. On the other hand, the studied train rides mostly went through rural areas where exposure is typically lower. Secondly, in a train one is constantly in close proximity to other users, with a high likelihood for at least some of them to be active users, since people use their mobile devices on a train as a pastime, to work etc. Moreover, during train rides, mobile devices have to switch communications between base stations regularly, each time performing handovers during which the power output of the device is elevated (Urbinello et al., 2014c). Based on a rough count, we divided train rides in rush $(>20$ people per wagon) and non-rush ( $<20$ people per wagon) hours. We observed a significantly higher exposure during rush (mean of $2.31 \mathrm{~mW} / \mathrm{m}^{2}$ ) than during non-rush (mean of 0.17 $\mathrm{mW} / \mathrm{m}^{2}$ ), strengthening our assumption that at least a fraction of train travellers are active users. Sagar et al. (2016) found $0.37 \mathrm{~mW} / \mathrm{m}^{2}$ average uplink exposure during train rides, which is in between our findings for rush and non-rush hours. This represented $65 \%$ of total exposure. Joseph et al. (2010) found average uplink exposures of $1.97 \mathrm{~mW} / \mathrm{m}^{2}(87 \%$ of total exposure) and $2.56 \mathrm{~mW} / \mathrm{m}^{2}(86 \%$ of total exposure) during train rides in Belgium and Switzerland respectively, which is comparable to our values.

The temporal evolution on a Saturday in the shopping area in Bruges was as expected in terms of the uplink exposure (Figure 6b): at the times when it was most busy, there were more users present, so more uplink exposure was measured. When there were more users, one could expect base stations to emit more power, so downlink exposure should follow the same trend. However, Figure 6a shows the opposite for the downlink. Figure $6 \mathrm{c}$ shows the broadcast exposure, which was expected to be constant but exhibited the same behaviour as the downlink exposure. Because of the high number of people in a shopping area, a potential reason for this trend is that a significant amount of radiation from the downlink and broadcasting base stations was blocked by bystanders, leading to lower measurement values and therefore a lower average exposure per person from these sources. 
If we compare the cities in terms of exposure measured during the temporal measurements, the total exposure in both residential and industrial areas was highest in Bruges and lowest in Ghent across timeslots (Figure 5). This was in contrast with the results from the spatial measurements. The difference in downlink exposure might be due to the positioning of base stations relative to the path along which the measurements were conducted. To avoid any biases, we did not investigate base station locations prior to the measurements.

\subsubsection{Representativeness}

We assessed the representativeness of our measurement protocol by calculating Spearman's correlation coefficient between summary statistics of two crossing paths in eight microenvironments. We obtained high correlations ( $r>0.83$, Table 6 and Figure 7$)$ for the median of downlink, broadcast, others and total exposure. This shows that measurements along these paths were representative for their respective microenvironments and that measurements during different timeslots undergo a similar transformation across different paths for these technologies. For uplink exposure, we could not find a significant correlation between crossing paths. The representativeness of this protocol was also studied by other authors. Thielens et al. (2018) found correlations of $r>0.60$ for different summary statistics in 15 microenvironments and Sagar et al. (2016) found $r>0.55$ for the arithmetic means of different paths in 31 microenvironments. These papers also showed repeatability for the uplink bands, which might be due to the fact that they tested more microenvironments. So they both have an increased sample size compared to our paper.

\subsection{On-body calibration}

The median values of the response (Table C2) were mostly below $0 \mathrm{~dB}$, in 15 of 26 cases these were between -2 and $-5 \mathrm{~dB}$. This is equivalent to an underestimation by a factor between 1.6 and 3.2. This confirmed that some of the radiation was absorbed or scattered away by the body before reaching the ExpoM-RF. In four cases (Wifi-5G for both researchers and 900 and $2600 \mathrm{MHz}$ downlink for researcher 1) more than $50 \%$ of the exposure situations resulted in an overestimation of measurements from body-worn devices. Overestimations were most likely due to radiation being reflected from the body back to the device, diffraction around the body, or a mismatch between the calibration signal and the detection scheme in the device. The asymmetry in the distribution of the response was because of asymmetric absorption and reflection of the human body (Thielens et al., 2015) as function of the angle of incidence. The responses from both on-body positions were consistent, having the same bands with the highest and lowest responses. In terms of the $50^{\text {th }}$ and $84^{\text {th }}$ percentiles, there was no position which had the highest response consistently. The $16^{\text {th }}$ percentile however was always lower for researcher 2. This can be due to differences in body composition or to the position of the ExpoM-RF on the body. Researcher 1 wore the ExpoM-RF in a jacket pocket, researcher 2 wore the ExpoMRF in a backpack, where it was closer to most parts of the body and thus was possibly more influenced by absorption of radiation by the body. Aminzadeh et al. (2016) and Thielens et al. (2015) obtained similar results using a similar calibration method. The on-body measurement uncertainty, which is proportional to the ratio of the $84^{\text {th }}$ and $16^{\text {th }}$ percentile of the exposimeter's response, is larger in UL bands than in the corresponding DL bands (see Table C2). Since the 
researchers' own devices were shut down during measurements, we assume all UL exposure to come from sources in the device's far field with a uniformly distributed polarization.

\subsection{Strengths and limitations}

This is the first time a systematic comparison of five cities (four of which in the same region) in Belgium was performed using matching microenvironments in each city. This comparison allowed us to show a potential impact of different regulations on exposure to RF-EMF radiation of the population and might help in the interpretation of previously published results. The measurements were performed by a researcher with an on-body calibrated personal exposimeter both during and outside of office hours. Timeslots outside of office hours have barely been investigated previously using this method. Consequently, our results lead to new insights in the variations of exposure over time. Additionally, the on-body calibrations of the ExpoM-RF provides a better context for the obtained results compared to results that are reported without on-body calibration. The results in this study showed high representativeness and high repeatability, which makes them reliable data sources for future reference. Moreover, our findings allow for more efficient measurement planning for similar studies in the future by relying on the protocols demonstrated and validated in this paper.

The study has some limitations. The presence of non-detects was high in certain frequency bands. Consequently, the substitution by $\mathrm{LOD} / \sqrt{2}$ could lead to some bias in summary statistics for some distributions and could have an influence on the meta-analyses executed using these statistics. On the other hand, the relatively simple method does not lead to much loss in accuracy in comparison to higher-order substitution methods (Hewett and Ganser, 2007). The classification of our measurements in rush and non-rush categories was determined a priori, which could lead to misclassification. This classification could be improved by simultaneously measuring other non-RF-EMF population characteristics. Finally, we did not perform an a posteriori analysis of the relationship between our measurements and the sources of exposure (RF-EMF base stations and broadcast antennas), while there are other papers that do demonstrate this relationship (Martens et al., 2015). However, our on-body calibration does provide us with a fixed relationship between incident RF-EMFs and the measured exposure values.

\section{Conclusions}

Personal exposure to RF-EMFs was studied using microenvironmental measurements in five cities in Flanders and the Brussels Capital Region. Highest total exposure values were found in Brussels (2.63 $\mathrm{mW} / \mathrm{m}^{2}$ averaged over five microenvironments). Our analysis showed that the amount of RF-EMF radiation in a certain environment was dependent on the population density within that environment. A higher average downlink exposure was measured in Antwerp in comparison to Brussels whilst having a lower population density. This might be an effect of the stronger legislation on base stations in Brussels. Downlink was the largest contributor to total exposure. The total RF-EMF exposure was significantly higher during rush than during non-rush hours. Furthermore, the total exposure was highest at night compared to 
other timeslots. The selected paths showed to be representative for exposure in their respective microenvironments. The results were also found to be repeatable. The used measurement devices were calibrated on the body of the researchers that wore them during measurements. These calibrations showed that the devices underestimate the personal exposure since median underestimations were measured in a majority of the studied frequency bands on the bodies of the two individual researchers, respectively.

\section{Acknowledgements}

A.T. has received funding from the European Union's Horizon 2020 research and innovation programme under the Marie Skłodowska-Curie grant agreement No 665501 with the FWO. A.T. is an FWO [PEGASUS] ${ }^{2}$ Marie Skłodowska-Curie Fellow. 


\section{Appendix A: Characteristics of the ExpoM-RF}

Table A1: Overview of the frequency bands and the sensitivity range (lower and upper limit of detection (LOD)) of the ExpoM-RF. UL stands for uplink, while DL stands for downlink (Fields at work GmbH, Zürich, Switzerland).

\begin{tabular}{lcc}
\hline Service & $\begin{array}{c}\text { Frequency range } \\
\text { (MHz) }\end{array}$ & $\begin{array}{c}\text { Sensitivity range: } \\
\text { Lower LOD }- \\
\text { upper LOD }(\mathbf{V} / \mathbf{m})\end{array}$ \\
\hline FM Radio & $87.5-108$ & $0.02-5$ \\
DVB-T & $470-790$ & $0.005-5$ \\
800 DL & $791-821$ & $0.005-5$ \\
800 UL & $832-862$ & $0.005-5$ \\
900 UL & $880-915$ & $0.005-5$ \\
900 DL & $925-960$ & $0.005-5$ \\
1800 UL & $1710-1785$ & $0.005-5$ \\
1800 DL & $1805-1880$ & $0.005-5$ \\
DECT & $1880-1900$ & $0.005-5$ \\
2100 UL & $1920-1980$ & $0.003-5$ \\
2100 DL & $2110-2170$ & $0.003-5$ \\
Wifi 2G & $2400-2485$ & $0.005-5$ \\
2600 UL & $2500-2570$ & $0.003-5$ \\
2600 DL & $2620-2690$ & $0.003-5$ \\
WiMax 3.5 & $3400-3600$ & $0.003-5$ \\
Wifi-5G & $5150-5875$ & $0.01-5$ \\
\hline
\end{tabular}

\section{Appendix B: Overview of studied cities and microenvironments}

Table B1: Population density of each of the studied cities (Retrieved from www.vlaanderen.be on 31/01/2019).

\begin{tabular}{lc}
\hline City & Population density (\# people/km²) \\
\hline Brussels & 7407 \\
Antwerp & 2551 \\
Ghent & 1662 \\
Bruges & 854 \\
Hasselt & 759 \\
\hline
\end{tabular}


Table B2: Location of the studied microenvironments for the spatial analysis

\begin{tabular}{lll}
\hline Microenvironment & City & Type \\
\hline Trawoollaan, Machelen & Brussels & Industrial \\
\hline Kraaienwijk & Brussels & Residential \\
\hline Warandepark & Brussels & Park \& Recreation \\
\hline Nieuwstraat & Brussels & Shopping \\
\hline Brussels Central Station & Brussels & Train Station \\
\hline Industrieweg, Wondelgem & Ghent & Industrial \\
\hline Coupure - Stoppelstraat & Ghent & Residential \\
\hline Citadelpark & Ghent & Park \& Recreation \\
\hline Veldstraat & Ghent & Shopping \\
\hline Station Gent Sint-Pieters & Ghent & Train Station \\
\hline Groothandelsmarkt & Antwerp & Industrial \\
\hline Klein-Antwerpen & Antwerp & Residential \\
\hline Stadspark & Antwerp & Park \& Recreation \\
\hline Meir & Antwerp & Shopping \\
\hline Antwerp Central station & Antwerp & Train Station \\
\hline Grenslandhallen & Hasselt & Industrial \\
\hline Vlinder & Hasselt & Residential \\
\hline Kapermolenpark & Hasselt & Park \& Recreation \\
\hline Koning Albertstraat - Demerstraat & Hasselt & Shopping \\
\hline Station Hasselt & Hasselt & Train Station \\
\hline Blauwe Toren & Bruges & Industrial \\
\hline Titecastraat - Barrièrestraat & Bruges & Residential \\
\hline Minnewaterpark & Bruges & Park \& Recreation \\
\hline Steenstraat - Noordzandstraat & Bruges & Shopping \\
\hline Station Brugge & Bruges & Train Station \\
\hline
\end{tabular}

Table B3: Location of the microenvironments with their studied timeslots for the temporal analysis and representativeness

\begin{tabular}{llll}
\hline Microenvironment & City & Type & Timeslots \\
\hline Industrielaan, Anderlecht & Brussels & Industrial & Rush, non-rush, night \\
\hline Sint-Gillis & Brussels & Residential & Rush, non-rush, night \\
\hline Gentbrugge II & Ghent & Industrial & Rush, non-rush \\
\hline Ledeberg & Ghent & Residential 1 & Rush, non-rush \\
\hline Sint-Pieters-Aaigem & Ghent & Residential 2 & / $^{\text {a }}$ \\
\hline Waggelwater & Bruges & Industrial & Rush, non-rush, night \\
\hline Vlamingdam - Leopold I-Laan & Bruges & Residential & Rush, non-rush, night \\
\hline Steenstraat - Noordzandstraat & Bruges & Shopping & Saturday \\
\hline \multicolumn{2}{l}{ Measurements in this microenvironment were only used to assess representativeness. } \\
\hline
\end{tabular}




\section{Appendix C: On-body calibration}

\section{C.1. Method}

Table C1 shows the 13 calibrated frequency bands. Measurements were conducted in an anechoic chamber, with a linearly polarised transmitting antenna (TX) radiating at a constant power. For each frequency band, the TX radiated at the central frequency, first with a horizontal polarisation $(\mathrm{H})$ and then with a vertical polarisation $(\mathrm{V})$. To calibrate the ExpoM-RF on the body of the researcher, firstly free-space measurements were executed: exposure was measured without a subject present. The incident electric field strengths were measured using a Narda NBM-550 broadband field meter (Narda, Hauppauge, NY, USA). This was done at heights of $63,94,125,150,178$ and $201 \mathrm{~cm}$ and averaged out for each polarisation. The free-space results are shown in Table C1. Differences between each polarisation can be attributed to small asymmetries in the anechoic chamber and minor anisotropies in the probe (Thielens et al. 2015). Next, on-body measurements were conducted with the researchers wearing the ExpoM-RF in the same position as during the measurements conducted throughout this research. This was in the pocket of a jacket for the researcher executing the spatial measurements and in a backpack for the researcher executing the temporal measurements. The individuals stood on a rotating platform, with rotating angle $\varphi$ going from 0 to $2 \pi$ in four minutes at a constant speed. The ExpoM-RF measured every three seconds, which resulted in 80 samples of $\varphi$, uniformly distributed from 0 to $2 \pi$. For each of the frequency bands the response $r_{i}$ was calculated, with $i$ from 1 to 13, for each of the calibrated frequency bands, using:

$$
r_{i}(\varphi)=\left(\frac{E_{i}^{b o d y}\left(f_{i}, \varphi\right)}{E_{i}^{\text {free }}\left(f_{i}\right)}\right)^{2}
$$

With $E_{i}^{b o d y}$ the electric field measured with the ExpoM-RF on the body of the researcher and $E_{i}^{\text {free }}$ the electric field measured in free-space. In a real exposure scenario the polarization of the electric field will not be exactly equal to $\mathrm{H}$ or $\mathrm{V}$. To find the response for realistic polarisations $\psi$, we combine both orthogonal polarisations in a sum of two orthogonal components:

$$
R_{i}(\varphi, \psi)=r_{i}^{H}(\varphi) \cos ^{2}(\psi)+r_{i}^{V}(\varphi) \sin ^{2}(\psi)
$$

The effect of polarisation was simulated using 1000 samples of $\psi$ drawn from the Gaussian distribution described in Kalliola et al. (2002) for the downlink bands and drawn from a uniform distribution from 0 to $2 \pi$ for the uplink, DECT, and WiFi bands. This is in line with Thielens et al. (2015). This leads to 80000 samples for $R_{i}$. The median, $\mathrm{p}_{16}$, and $\mathrm{p}_{84}$ of these 80000 samples were then determined. $R_{i}$ was then transformed to a dB scale:

$$
R_{i}(d B)=20 \times \log _{10}\left(R_{i}\right)
$$


Table C1: Studied frequency bands with their central frequencies, and incident electric fields averaged over the subject's height, for the horizontally $(H)$ and vertically $(V)$ polarised waves.

\begin{tabular}{|c|c|c|c|}
\hline $\begin{array}{l}\text { Frequency } \\
\text { band }\end{array}$ & $\begin{array}{c}\text { Central frequency } \\
\text { (MHz) }\end{array}$ & $E_{\text {free }, H}^{R M S}\left(\frac{V}{m}\right)$ & $E_{\text {free }, V}^{R M S}\left(\frac{V}{m}\right)$ \\
\hline $800 \mathrm{DL}$ & 806 & 0.28 & 0.24 \\
\hline $800 \mathrm{UL}$ & 847 & 0.28 & 0.25 \\
\hline $900 \mathrm{UL}$ & 896 & 0.30 & 0.28 \\
\hline $900 \mathrm{DL}$ & 941 & 0.27 & 0.31 \\
\hline $1800 \mathrm{UL}$ & 1748 & 0.26 & 0.26 \\
\hline $1800 \mathrm{DL}$ & 1843 & 0.27 & 0.26 \\
\hline DECT & 1890 & 0.30 & 0.30 \\
\hline $2100 \mathrm{UL}$ & 1940 & 0.30 & 0.29 \\
\hline $2100 \mathrm{DL}$ & 2140 & 0.46 & 0.46 \\
\hline Wifi 2G & 2443 & 0.36 & 0.32 \\
\hline $2600 \mathrm{UL}$ & 2535 & 0.32 & 0.28 \\
\hline $2600 \mathrm{DL}$ & 2655 & 0.31 & 0.27 \\
\hline Wifi-5G & 5513 & 0.20 & 0.20 \\
\hline
\end{tabular}

\section{C.2. Results}

The results of the free-space measurements are shown in Table C1. Measured free-space incident electric field strengths were in between $0.2 \mathrm{~V} / \mathrm{m}$ at Wifi-5G and $0.46 \mathrm{~V} / \mathrm{m}$ at $2100 \mathrm{DL}$. Table $\mathrm{C} 2$ shows the responses for researcher 1 and 2 . The median response values were smaller than 1 (negative values in $\mathrm{dB}$ ) for 8 out of 13 studied bands for researcher 1 and 11 out of 13 studied bands for researcher 2. A response smaller than 1 was expected for most bands since the body blocks and absorbs some of the radiation. These results are similar to the ones found by Thielens et al. (2015).

Table C2: Responses (medians, $\left.p_{50}\right)$ for researcher 1 and researcher 2 and their $16^{\text {th }}\left(p_{16}\right)$ and $84^{\text {th }}\left(p_{84}\right)$ percentiles.

\begin{tabular}{|c|c|c|c|c|}
\hline \multirow[t]{2}{*}{ Frequency band } & \multicolumn{2}{|c|}{ Researcher 1 [dB] } & \multicolumn{2}{|c|}{ Researcher $2[\mathrm{~dB}]$} \\
\hline & Response $\left(\boldsymbol{p}_{50}\right)$ & $\left(p_{16}, p_{84}\right)$ & Response $\left(\boldsymbol{p}_{50}\right)$ & $\left(p_{16}, p_{84}\right)$ \\
\hline $800 \mathrm{DL}$ & -2.32 & $(-5.44,0.54)$ & -0.78 & $(-8.33,4.35)$ \\
\hline $800 \mathrm{UL}$ & -3.00 & $(-11.6,1.65)$ & -3.51 & $(-14.1,0.81)$ \\
\hline $900 \mathrm{UL}$ & -5.07 & $(-13.1,0.89)$ & -4.73 & $(-13.7,1.69)$ \\
\hline $900 \mathrm{DL}$ & 0.23 & $(-5.78,3.25)$ & -1.26 & $(-8.25,3.34)$ \\
\hline $1800 \mathrm{UL}$ & -4.43 & $(-14.2,1.99)$ & -4.40 & $(-16.7,0.34)$ \\
\hline $1800 \mathrm{DL}$ & -4.22 & $(-11.1,-0.92)$ & -3.60 & $(-15.4,0.36)$ \\
\hline DECT & -4.71 & $(-13.9,-0.92)$ & -2.47 & $(-15.9,1.42)$ \\
\hline $2100 \mathrm{UL}$ & -3.92 & $(-13.8,-0.44)$ & -1.42 & $(-15.4,2.70)$ \\
\hline $2100 \mathrm{DL}$ & -3.93 & $(-8.84,0.34)$ & -3.00 & $(-13.6,1.76)$ \\
\hline Wifi 2G & -2.66 & $(-12.0,0.28)$ & -2.76 & $(-12.3,1.06)$ \\
\hline $2600 \mathrm{UL}$ & -1.11 & $(-9.67,1.49)$ & -1.69 & $(-11.8,1.79)$ \\
\hline $2600 \mathrm{DL}$ & 1.77 & $(-4.47,4.45)$ & -1.01 & $(-9.91,3.26)$ \\
\hline Wifi-5G & 7.86 & $(-0.35,11.4)$ & 4.53 & $(-5.69,9.19)$ \\
\hline
\end{tabular}




\section{Appendix D: Detailed descriptive statistics}

The results in Tables D1 and D2 are presented in five categories. This is further explained in Section 2.3. The frequency bands categorized under downlink (DL) are: Mobile 800 DL (791 - $821 \mathrm{MHz})$, Mobile 900 DL (923 - $960 \mathrm{MHz})$, Mobile 1800 DL (1805 - 1880 MHz), Mobile 2100 DL (2110 - 2170 MHz) and Mobile 2600 DL $(2620-2690 \mathrm{MHz})$. The frequency bands categorized under uplink (UL) are: Mobile $800 \mathrm{UL}(832-862 \mathrm{MHz})$, Mobile $900 \mathrm{UL}$ ( $880-915$ MHz), Mobile $1800 \mathrm{UL}(1710-1785 \mathrm{MHz})$, Mobile $2100 \mathrm{UL}(1920-1980 \mathrm{MHz})$ and Mobile $2600 \mathrm{UL}(2500-2570 \mathrm{MHz})$. The frequency bands categorized under Broadcast are: FM $(87.5-108 \mathrm{MHz})$ and TV $(470-790 \mathrm{MHz})$. Lastly, the frequency bands categorized under Other are: DECT (1880 - $1900 \mathrm{MHz})$, Wifi 2G (2400 - 2485 MHz), Mobile $3500(3400-3600 \mathrm{MHz})$ and Wifi 5G (5150 - 5875 MHz).

Table D1: Summary statistics of S measurements using the ExpoM-RF during different timeslots in Bruges, Ghent and Brussels and during train rides.

\begin{tabular}{|c|c|c|c|c|c|c|c|c|c|c|c|c|c|c|c|c|c|c|c|c|c|c|c|c|c|c|c|c|c|c|}
\hline \multirow[t]{2}{*}{$\mathrm{S}^{\mathrm{a}}\left(\mathbf{m W} / \mathbf{m}^{2}\right)$} & \multicolumn{6}{|c|}{ DL } & \multicolumn{6}{|c|}{$\mathbf{U L}$} & \multicolumn{6}{|c|}{ Broadcast } & \multicolumn{6}{|c|}{ Others } & \multicolumn{6}{|c|}{ Total } \\
\hline & $\mu$ & std & $p_{16}$ & $p_{50}$ & $p_{84}$ & $p_{95}$ & $\mu$ & std & $p_{16}$ & $p_{50}$ & $p_{84}$ & $p_{95}$ & $\mu$ & std & $p_{16}$ & $p_{50}$ & $p_{84}$ & $p_{95}$ & $\mu$ & std & $p_{16}$ & $p_{50}$ & $p_{84}$ & $p_{95}$ & $\mu$ & std & $p_{16}$ & $p_{50}$ & $p_{84}$ & $p_{95}$ \\
\hline \multicolumn{31}{|l|}{ Timeslot } \\
\hline \multicolumn{31}{|l|}{ Brussels } \\
\hline Rush & 0.58 & 1.30 & 0.02 & 0.18 & 0.91 & 2.40 & $9 \mathrm{e}-4$ & $7 e-3$ & $1 \mathrm{e}-4$ & $1 \mathrm{e}-4$ & $3 \mathrm{e}-4$ & $2 e-3$ & 0.05 & 0.06 & 0.01 & 0.03 & 0.08 & 0.14 & 0.03 & 0.07 & $4 e-3$ & 0.01 & 0.03 & 0.10 & 0.66 & 1.34 & 0.09 & 0.26 & 1.01 & 2.53 \\
\hline Non-rush & 0.44 & 0.89 & 0.02 & 0.15 & 0.73 & 1.86 & $2 e-3$ & 0.01 & $1 e-4$ & $1 e-4$ & $5 e-4$ & $3 e-3$ & 0.05 & 0.08 & 0.01 & 0.03 & 0.08 & 0.15 & 0.03 & 0.07 & $4 e-3$ & 0.01 & 0.03 & 0.08 & 0.52 & 0.94 & 0.08 & 0.23 & 0.83 & 1.98 \\
\hline $\begin{array}{l}\text { Night } \\
\text { Ghent }\end{array}$ & 0.82 & 1.61 & 0.02 & 0.24 & 1.49 & 4.01 & $3 e-3$ & 0.02 & $1 e-4$ & $1 e-4$ & $4 \mathrm{e}-4$ & $4 e-3$ & 0.05 & 0.04 & 0.02 & 0.03 & 0.08 & 0.13 & 0.03 & 0.09 & $4 e-3$ & 0.01 & 0.04 & 0.15 & 0.91 & 1.65 & 0.07 & 0.33 & 1.63 & 4.12 \\
\hline Rush & 0.12 & 0.23 & 0.02 & 0.05 & 0.17 & 0.52 & $1 e-4$ & $2 \mathrm{e}-4$ & $1 \mathrm{e}-4$ & $1 e-4$ & $1 \mathrm{e}-4$ & $2 e-4$ & 0.06 & 0.09 & 0.01 & 0.03 & 0.09 & 0.20 & 0.01 & 0.02 & $4 e-3$ & $4 e-3$ & 0.01 & 0.03 & 0.19 & 0.26 & 0.04 & 0.10 & 0.29 & 0.63 \\
\hline $\begin{array}{l}\text { Non-rush } \\
\text { Bruges }\end{array}$ & 0.13 & 0.23 & 0.02 & 0.05 & 0.18 & 0.53 & $1 e-4$ & $1 e-4$ & $1 e-4$ & $1 e-4$ & $1 e-4$ & $2 e-4$ & 0.05 & 0.08 & $8 \mathrm{e}-3$ & 0.02 & 0.08 & 0.19 & 0.01 & 0.02 & $4 e-3$ & $4 e-3$ & 0.01 & 0.02 & 0.18 & 0.25 & 0.04 & 0.10 & 0.30 & 0.60 \\
\hline Rush & 1.03 & 3.89 & 0.01 & 0.08 & 0.68 & 4.53 & $2 e-4$ & $6 e-4$ & $1 e-4$ & $1 e-4$ & $1 \mathrm{e}-4$ & $2 e-4$ & 0.06 & 0.13 & $3 e-3$ & 0.01 & 0.10 & 0.28 & 0.03 & 0.06 & $4 e-3$ & 0.01 & 0.05 & 0.13 & 1.12 & 3.91 & 0.05 & 0.18 & 0.78 & 4.83 \\
\hline Non-rush & 1.05 & 3.72 & 0.01 & 0.07 & 0.66 & 5.17 & $2 e-4$ & $3 e-4$ & $1 e-4$ & $1 e-4$ & $1 \mathrm{e}-4$ & $2 e-4$ & 0.07 & 0.16 & $3 e-3$ & 0.01 & 0.10 & 0.34 & 0.03 & 0.05 & $4 e-3$ & 0.01 & 0.05 & 0.13 & 1.14 & 3.74 & 0.04 & 0.17 & 0.83 & 5.36 \\
\hline Night & 1.13 & 3.66 & 0.01 & 0.07 & 0.64 & 8.25 & $1 e-4$ & $4 e-5$ & $1 e-4$ & $1 e-4$ & $1 \mathrm{e}-4$ & $2 e-4$ & 0.07 & 0.14 & $5 e-3$ & 0.02 & 0.11 & 0.32 & 0.03 & 0.07 & $4 e-3$ & 0.01 & 0.04 & 0.16 & 1.24 & 3.68 & 0.05 & 0.17 & 0.78 & 8.55 \\
\hline $\begin{array}{l}\text { Saturday } \\
\text { Train }\end{array}$ & 0.64 & 1.53 & 0.03 & 0.10 & 1.03 & 3.14 & $2 e-3$ & $9 e-3$ & $1 e-4$ & $2 \mathrm{e}-4$ & $1 \mathrm{e}-3$ & $5 e-3$ & 0.02 & 0.06 & $3 e-3$ & 0.01 & 0.04 & 0.11 & 0.02 & 0.03 & $5 e-3$ & 0.01 & 0.02 & 0.07 & 0.68 & 1.55 & 0.05 & 0.13 & 1.08 & 3.22 \\
\hline Rush & 0.02 & 0.06 & $1 e-3$ & $4 e-3$ & 0.03 & 0.08 & 2.13 & 8.15 & $3 e-3$ & 0.04 & 1.20 & 11.2 & $4 e-3$ & 0.02 & $6 e-4$ & $6 e-4$ & $2 e-3$ & 0.01 & $5 e-3$ & $7 e-3$ & $3 e-3$ & $4 e-3$ & $5 e-3$ & 0.01 & 2.16 & 8.14 & 0.02 & 0.08 & 1.23 & 11.2 \\
\hline Non-rush & 0.03 & 0.09 & $1 \mathrm{e}-3$ & $4 \mathrm{e}-3$ & 0.03 & 0.12 & 0.17 & 0.45 & $6 \mathrm{e}-4$ & 0.01 & 0.28 & 0.95 & 0.01 & 0.06 & $6 e-4$ & $7 \mathrm{e}-4$ & $3 e-3$ & 0.03 & $4 e-3$ & $5 e-3$ & $3 e-3$ & $3 \mathrm{e}-3$ & $4 \mathrm{e}-3$ & $7 \mathrm{e}-3$ & 0.21 & 0.45 & 0.01 & 0.06 & 0.35 & 1.01 \\
\hline
\end{tabular}


Table D2: Summary statistics of S measurements using the ExpoM-RF in 25 microenviroments in five cities in the Flemish Region and the Brussels Capital Region.

\begin{tabular}{|c|c|c|c|c|c|c|c|c|c|c|c|c|c|c|c|c|c|c|c|c|c|c|c|c|c|c|c|c|c|c|}
\hline \multirow[t]{2}{*}{$\mathrm{S}^{\mathrm{a}}\left(\mathrm{mW} / \mathrm{m}^{2}\right)$} & \multicolumn{6}{|c|}{ DL } & \multicolumn{6}{|c|}{$\mathbf{U L}$} & \multicolumn{6}{|c|}{ Broadcast } & \multicolumn{6}{|c|}{ Others } & \multicolumn{6}{|c|}{ Total } \\
\hline & $\mu$ & std & $p_{16}$ & $p_{50}$ & $p_{84}$ & $p_{95}$ & $\mu$ & std & $p_{16}$ & $p_{50}$ & $p_{84}$ & $p_{95}$ & $\mu$ & std & $p_{16}$ & $p_{50}$ & $p_{84}$ & $p_{95}$ & $\mu$ & std & $p_{16}$ & $p_{50}$ & $p_{84}$ & $p_{95}$ & $\mu$ & std & $p_{16}$ & $p_{50}$ & $p_{84}$ & $p_{95}$ \\
\hline \multicolumn{31}{|l|}{ Microenvironment } \\
\hline \multicolumn{31}{|l|}{ Brussels } \\
\hline Industrial & 1.10 & 1.03 & 0.28 & 0.74 & 2.03 & 2.85 & $3 e-4$ & $3 e-4$ & $1 \mathrm{e}-4$ & $2 \mathrm{e}-4$ & $4 \mathrm{e}-4$ & $9 \mathrm{e}-4$ & 0.01 & $4 e-3$ & $4 e-3$ & 0.01 & 0.01 & 0.02 & 0.05 & 0.05 & 0.01 & 0.03 & 0.09 & 0.16 & 1.16 & 1.07 & 0.30 & 0.78 & 2.11 & 2.94 \\
\hline Residential & 0.24 & 0.29 & 0.03 & 0.15 & 0.43 & 0.71 & $3 e-4$ & $1 e-3$ & $1 e-4$ & 1e-4 & $2 \mathrm{e}-4$ & $7 e-4$ & 0.81 & 1.49 & 0.12 & 0.43 & 1.09 & 2.21 & 0.01 & 0.02 & $4 e-3$ & 0.01 & 0.02 & 0.05 & 1.06 & 1.54 & 0.27 & 0.68 & 1.50 & 2.37 \\
\hline Park \& Recreation & 0.17 & 0.32 & 0.03 & 0.06 & 0.28 & 0.69 & $3 e-4$ & $7 e-4$ & 1e-4 & $1 e-4$ & $2 \mathrm{e}-4$ & $6 e-4$ & 7.66 & 10.6 & 2.23 & 4.61 & 10.4 & 29.3 & 0.01 & $4 e-3$ & $4 e-3$ & $4 e-3$ & 0.01 & 0.01 & 7.83 & 10.7 & 2.42 & 4.76 & 10.5 & 29.4 \\
\hline Shopping & 2.06 & 4.53 & 0.04 & 0.41 & 4.06 & 6.78 & $3 e-3$ & $7 \mathrm{e}-3$ & $3 e-4$ & $8 e-4$ & $4 \mathrm{e}-3$ & 0.01 & 0.60 & 0.39 & 0.27 & 0.50 & 1.00 & 1.31 & 0.06 & 0.17 & 0.01 & 0.02 & 0.06 & 0.18 & 2.72 & 4.44 & 0.64 & 1.28 & 4.74 & 7.19 \\
\hline Train Station & 0.27 & 0.56 & 0.02 & 0.10 & 0.36 & 1.05 & $3 e-3$ & $4 e-3$ & $4 e-4$ & $1 e-3$ & $4 \mathrm{e}-3$ & 0.01 & 0.09 & 0.66 & 0.00 & 0.01 & 0.03 & 0.10 & 0.02 & 0.05 & $5 e-3$ & 0.01 & 0.02 & 0.07 & 0.38 & 1.04 & 0.05 & 0.14 & 0.38 & 1.22 \\
\hline Ghent & & & & & & & & & & & & & & & & & & & & & & & & & & & & & & \\
\hline Industrial & 0.21 & 0.35 & 0.04 & 0.08 & 0.27 & 0.96 & $1 \mathrm{e}-4$ & 1e-4 & 1e-4 & 1e-4 & $1 \mathrm{e}-4$ & $2 \mathrm{e}-4$ & 0.01 & 0.01 & $3 e-3$ & 0.01 & 0.01 & 0.02 & 0.01 & 0.01 & $4 e-3$ & $5 e-3$ & 0.01 & 0.02 & 0.22 & 0.36 & 0.05 & 0.10 & 0.28 & 0.98 \\
\hline Residential & 0.16 & 0.18 & 0.01 & 0.09 & 0.33 & 0.60 & $1 e-4$ & $7 e-5$ & $1 e-4$ & $1 e-4$ & $1 e-4$ & $2 \mathrm{e}-4$ & 0.62 & 1.07 & 0.06 & 0.18 & 0.99 & 2.85 & 0.01 & 0.01 & $4 e-3$ & 0.01 & 0.01 & 0.02 & 0.79 & 1.17 & 0.10 & 0.39 & 1.27 & 3.08 \\
\hline Park \& Recreation & 0.27 & 0.49 & 0.04 & 0.14 & 0.44 & 0.97 & $1 e-4$ & $2 \mathrm{e}-4$ & 1e-4 & 1e-4 & $1 \mathrm{e}-4$ & 1e-4 & 0.64 & 0.85 & 0.11 & 0.32 & 1.12 & 2.35 & 0.01 & 0.01 & $3 e-3$ & $4 e-3$ & 0.01 & 0.02 & 0.92 & 0.96 & 0.24 & 0.61 & 1.47 & 2.77 \\
\hline Shopping & 0.93 & 0.87 & 0.19 & 0.77 & 1.54 & 2.58 & $2 e-3$ & 0.01 & le-4 & $2 e-4$ & $6 e-4$ & $6 e-3$ & 0.07 & 0.06 & 0.02 & 0.05 & 0.11 & 0.19 & 0.07 & 0.08 & 0.01 & 0.03 & 0.17 & 0.20 & 1.07 & 0.92 & 0.27 & 0.97 & 1.71 & 2.79 \\
\hline Train Station & 0.36 & 1.97 & $8 e-4$ & $2 \mathrm{e}-3$ & $3 e-3$ & 0.09 & 0.01 & 0.03 & $2 e-3$ & $5 e-3$ & 0.01 & 0.03 & 0.02 & 0.03 & 0.01 & 0.02 & 0.02 & 0.06 & 0.05 & 0.28 & $4 e-3$ & $4 e-3$ & 0.01 & 0.04 & 0.44 & 2.26 & 0.02 & 0.03 & 0.06 & 0.36 \\
\hline \multicolumn{31}{|l|}{ Antwerp } \\
\hline Industrial & 4.05 & 6.82 & 0.25 & 1.82 & 6.10 & 16.5 & $2 \mathrm{e}-4$ & $2 \mathrm{e}-4$ & $1 \mathrm{e}-4$ & $1 \mathrm{e}-4$ & $2 \mathrm{e}-4$ & $3 e-4$ & 0.02 & 0.02 & $4 e-3$ & 0.01 & 0.02 & 0.04 & 0.17 & 0.36 & 0.01 & 0.04 & 0.32 & 0.68 & 4.24 & 7.11 & 0.26 & 1.89 & 6.61 & 17.5 \\
\hline Residential & 0.88 & 3.66 & 0.02 & 0.20 & 1.00 & 2.43 & $2 e-4$ & $4 e-4$ & le-4 & $1 e-4$ & $2 e-4$ & $5 e-4$ & 0.05 & 0.12 & 0.01 & 0.02 & 0.07 & 0.17 & 0.04 & 0.22 & $4 e-3$ & 0.01 & 0.03 & 0.11 & 0.97 & 3.84 & 0.06 & 0.26 & 1.08 & 2.55 \\
\hline Park \& Recreation & 0.11 & 0.16 & 0.03 & 0.05 & 0.17 & 0.46 & $1 e-4$ & $4 e-5$ & $1 e-4$ & 1e-4 & $1 \mathrm{e}-4$ & $2 \mathrm{e}-4$ & 0.32 & 0.27 & 0.13 & 0.21 & 0.52 & 0.91 & 0.01 & 0.02 & $4 e-3$ & 0.01 & 0.01 & 0.02 & 0.45 & 0.40 & 0.19 & 0.27 & 0.75 & 1.21 \\
\hline Shop & 1.40 & 2.70 & 0.04 & 0.33 & 2.45 & 6.25 & $2 e-3$ & $8 e-3$ & 1e-4 & $3 e-4$ & $1 \mathrm{e}-3$ & $4 e-3$ & 2.84 & 5.89 & 0.24 & 0.72 & 4.37 & 13.9 & 0.10 & 0.24 & 0.01 & 0.02 & 0.12 & 0.59 & 4.34 & 6.13 & 0.37 & 2.13 & 8.17 & 16.7 \\
\hline Train Station & 0.57 & 0.69 & 0.01 & 0.34 & 1.07 & 2.05 & $1 e-3$ & $4 e-3$ & $2 \mathrm{e}-4$ & $3 e-4$ & $1 \mathrm{e}-3$ & $4 e-3$ & 0.47 & 0.47 & 0.02 & 0.34 & 0.99 & 1.41 & 0.07 & 0.08 & $5 e-3$ & 0.04 & 0.14 & 0.23 & 1.11 & 1.12 & 0.03 & 0.85 & 2.15 & 3.37 \\
\hline \multicolumn{31}{|l|}{ Hasselt } \\
\hline Industrial & 0.04 & 0.05 & 0.01 & 0.02 & 0.06 & 0.12 & $5 e-4$ & $2 e-3$ & 1e-4 & $1 e-4$ & $5 e-4$ & $2 \mathrm{e}-3$ & 0.09 & 0.10 & 0.02 & 0.06 & 0.14 & 0.28 & $4 e-3$ & $9 \mathrm{e}-4$ & $4 e-3$ & $4 e-3$ & $4 e-3$ & 0.01 & 0.13 & 0.12 & 0.04 & 0.09 & 0.22 & 0.41 \\
\hline Residential & 0.25 & 0.44 & 0.04 & 0.11 & 0.40 & 0.83 & $2 e-4$ & $6 e-4$ & $1 e-4$ & $1 e-4$ & $1 \mathrm{e}-4$ & $3 e-4$ & 0.08 & 0.07 & 0.02 & 0.06 & 0.14 & 0.23 & 0.01 & 0.01 & $4 e-3$ & 0.01 & 0.01 & 0.02 & 0.34 & 0.47 & 0.09 & 0.18 & 0.54 & 0.97 \\
\hline Park \& Recreation & 0.56 & 0.70 & 0.13 & 0.32 & 0.87 & 1.72 & $1 e-4$ & $6 e-6$ & $1 e-4$ & $1 e-4$ & $1 e-4$ & $1 e-4$ & 1.31 & 1.58 & 0.15 & 0.69 & 2.65 & 4.47 & 0.01 & 0.01 & $5 e-3$ & 0.01 & 0.01 & 0.03 & 1.87 & 1.66 & 0.48 & 1.28 & 3.41 & 5.18 \\
\hline Shopping & 0.30 & 0.54 & 0.04 & 0.15 & 0.42 & 1.12 & $1 e-3$ & $7 e-3$ & le-4 & $2 \mathrm{e}-4$ & $9 \mathrm{e}-4$ & $6 e-3$ & 0.13 & 0.29 & 0.01 & 0.02 & 0.21 & 0.58 & 0.01 & 0.05 & $5 e-3$ & 0.01 & 0.01 & 0.03 & 0.45 & 0.65 & 0.09 & 0.25 & 0.65 & 1.79 \\
\hline Train Station & 0.30 & 0.58 & 0.01 & 0.13 & 0.22 & 1.93 & $4 e-4$ & $3 e-3$ & $1 e-4$ & $2 \mathrm{e}-4$ & $4 \mathrm{e}-4$ & $7 e-4$ & 0.02 & 0.22 & $6 e-4$ & $1 \mathrm{e}-3$ & 0.02 & 0.03 & 0.01 & 0.02 & $4 e-3$ & 0.01 & 0.02 & 0.06 & 0.34 & 0.63 & 0.01 & 0.14 & 0.25 & 2.07 \\
\hline \multicolumn{31}{|l|}{ Bruges } \\
\hline Indus & 0.42 & 0.41 & 0.12 & 0.28 & 0.68 & 1.32 & $1 e-4$ & $3 e-5$ & 1e-4 & 1e-4 & $1 e-4$ & $2 \mathrm{e}-4$ & 0.01 & 0.01 & $2 e-3$ & $5 e-3$ & 0.01 & 0.02 & 0.01 & $4 e-3$ & $4 e-3$ & $4 e-3$ & 0.01 & 0.01 & 0.43 & 0.41 & 0.13 & 0.29 & 0.70 & 1.33 \\
\hline Residential & 0.12 & 0.44 & $2 e-3$ & 0.01 & 0.09 & 0.69 & $1 e-3$ & 0.02 & $1 e-4$ & $1 e-4$ & $1 \mathrm{e}-4$ & $5 e-4$ & 0.03 & 0.03 & 0.01 & 0.02 & 0.06 & 0.10 & 0.01 & 0.03 & $3 e-3$ & $4 e-3$ & 0.01 & 0.03 & 0.17 & 0.46 & 0.02 & 0.05 & 0.15 & 0.83 \\
\hline Park \& Recreation & 0.06 & 0.11 & 0.01 & 0.02 & 0.10 & 0.21 & $2 e-4$ & $5 e-4$ & $1 e-4$ & 1e-4 & $1 \mathrm{e}-4$ & $4 e-4$ & 0.06 & 0.09 & 0.01 & 0.03 & 0.11 & 0.29 & 0.01 & 0.01 & $4 e-3$ & $4 e-3$ & 0.01 & 0.01 & 0.13 & 0.17 & 0.03 & 0.06 & 0.27 & 0.46 \\
\hline Shopping & 0.25 & 0.51 & 0.03 & 0.09 & 0.35 & 0.92 & $2 e-3$ & $9 e-3$ & $1 e-4$ & $3 e-4$ & $1 e-3$ & $5 e-3$ & 0.03 & 0.03 & 0.01 & 0.02 & 0.04 & 0.07 & 0.01 & 0.01 & $4 e-3$ & $5 e-3$ & 0.01 & 0.02 & 0.28 & 0.51 & 0.05 & 0.14 & 0.38 & 0.94 \\
\hline Train Station & 0.04 & 0.02 & 0.02 & 0.04 & 0.05 & 0.06 & $2 e-3$ & $5 e-3$ & $5 e-4$ & $1 \mathrm{e}-3$ & $4 \mathrm{e}-3$ & $9 e-3$ & $3 e-3$ & 0.01 & $6 e-4$ & $8 \mathrm{e}-4$ & $2 \mathrm{e}-3$ & 0.01 & 0.01 & 0.01 & $4 \mathrm{e}-3$ & 0.01 & 0.02 & 0.02 & 0.05 & 0.02 & 0.03 & 0.05 & 0.07 & 0.08 \\
\hline
\end{tabular}




\section{REFERENCES}

Aerts, S., Wiart, J., Martens, L., \& Joseph, W. (2018). Assessment of long-term spatiotemporal radiofrequency electromagnetic field exposure. Environmental Research, 161, 136-143. https://doi.org/10.1016/j.envres.2017.11.003

Aminzadeh, R., Thielens, A., Agneessens, S., Van Torre, P., Van den Bossche, M., Dongus, S., ... Joseph, W. (2018). A Multi-Band Body-Worn Distributed Radio-Frequency Exposure Meter: Design, On-Body Calibration and Study of Body Morphology. Sensors, 18(1), 272. https://doi.org/10.3390/s18010272

Aminzadeh, R., Thielens, A., Bamba, A., Kone, L., Gaillot, D. P., Lienard, M., ... Joseph, W. (2016). On-body calibration and measurements using personal radiofrequency exposimeters in indoor diffuse and specular environments: Calibration of Personal Exposimeters. Bioelectromagnetics, 37(5), 298-309. https://doi.org/10.1002/bem.21975

Bhatt, C. R., Thielens, A., Billah, B., Redmayne, M., Abramson, M. J., Sim, M. R., ... Benke, G. (2016a). Assessment of personal exposure from radiofrequencyelectromagnetic fields in Australia and Belgium using on-body calibrated exposimeters. Environmental Research, 151, 547-563. https://doi.org/10.1016/j.envres.2016.08.022

Bhatt, C. R., Thielens, A., Redmayne, M., Abramson, M. J., Billah, B., Sim, M. R., ... Benke, G. (2016b). Measuring personal exposure from 900MHz mobile phone base stations in Australia and Belgium using a novel personal distributed exposimeter. Environment International, 92-93, 388-397. https://doi.org/10.1016/j.envint.2016.03.032

BIPT, Belgisch Instituut voor postdiensten en telecommunicatie, Antenna Sites Register, publicly available on: http://www.sites.bipt.be (accessed on 24 december 2018).

Birks, L. E., Struchen, B., Eeftens, M., van Wel, L., Huss, A., Gajšek, P., ... Guxens, M. (2018). Spatial and temporal variability of personal environmental exposure to radio frequency electromagnetic fields in children in Europe. Environment International, 117, 204-214. https://doi.org/10.1016/j.envint.2018.04.026

Bolte, J. F. B. (2016). Lessons learnt on biases and uncertainties in personal exposure measurement surveys of radiofrequency electromagnetic fields with exposimeters. Environment International, 94, 724-735. https://doi.org/10.1016/j.envint.2016.06.023

Bolte, J. F. B., \& Eikelboom, T. (2012). Personal radiofrequency electromagnetic field measurements in the Netherlands: Exposure level and variability for everyday activities, times of day and types of area. Environment International, 48, 133-142. https://doi.org/10.1016/j.envint.2012.07.006

Brussels Capital Region. Ordinance of the Brussels Capital Region of 10 December 2013 (in Dutch and French): proposition of ordinance concerning the protection of the environment against the harmful effects and hindrance of non-ionizing radiation. Available on: http://weblex.irisnet.be/data/crb/doc/2013-14/124369/images.pdf.

Frei, P., Mohler, E., Neubauer, G., Theis, G., Bürgi, A., Fröhlich, J., ... Röösli, M. (2009). Temporal and spatial variability of personal exposure to radio frequency 
electromagnetic fields. Environmental Research, 109(6), 779-785.

https://doi.org/10.1016/j.envres.2009.04.015

Flemish Region. Resolution of the Flemish Government on the modification of the resolution of the Flemish Government of 1 June 1995 concerning general and sectorial provisions relating to environmental Safety and the resolution of Flemish Government of 12 December 2008 on the implementation of the decree of 5 April 1995 concerning general provisions relating to environmental policy, concerning the standardization of permanently installed transmitting antennas for electromagnetic waves between 10 $\mathrm{MHz}$ and $10 \mathrm{GHz}$. Design of Resolution, approved in principle in 1st reading by the Flemish Government 2 April 2010 considering requests for advice.

Ganser, G. H., \& Hewett, P. (2010). An Accurate Substitution Method for Analyzing Censored Data. Journal of Occupational and Environmental Hygiene, 7(4), 233-244. https://doi.org/10.1080/15459621003609713

ICNIRP. (1998). The International Commission on Non-ionizing Radiation Protection. Guidelines for limiting exposure to time-varying electric, magnetic, and electromagnetic fields ( up to $300 \mathrm{GHz}$ ). Health Phys. 74 (4), 494-522.

Joseph, W., Vermeeren, G., Verloock, L., Heredia, M. M., \& Martens, L. (2008). CHARACTERIZATION OF PERSONAL RF ELECTROMAGNETIC FIELD EXPOSURE AND ACTUAL ABSORPTION FOR THE GENERAL PUBLIC. Health Physics, 95(3), 317. https://doi.org/10.1097/01.HP.0000318880.16023.61

Joseph, Wout, Frei, P., Roösli, M., Thuróczy, G., Gajsek, P., Trcek, T., ... Martens, L. (2010). Comparison of personal radio frequency electromagnetic field exposure in different urban areas across Europe. Environmental Research, 110(7), 658-663. https://doi.org/10.1016/j.envres.2010.06.009

Joseph, Wout, \& Verloock, L. (2010). INFLUENCE OF MOBILE PHONE TRAFFIC ON BASE STATION EXPOSURE OF THE GENERAL PUBLIC: Health Physics, 99(5), 631-638. https://doi.org/10.1097/HP.0b013e3181db264f

Joseph, Wout, Verloock, L., Tanghe, E., \& Martens, L. (2009). In-Situ Measurement Procedures for Temporal RF Electromagnetic Field Exposure of the General Public: Health Physics, 96(5), 529-542. https://doi.org/10.1097/01.HP.0000341327.37310.c8

Mahfouz, Z., Gati, A., Lautru, D., Wong, M.-F., Wiart, J., \& Hanna, V. F. (2012). Influence of traffic variations on exposure to wireless signals in realistic environments. Bioelectromagnetics, 33(4), 288-297. https://doi.org/10.1002/bem.20705

Martens, A. L., Bolte, J. F. B., Beekhuizen, J., Kromhout, H., Smid, T., \& Vermeulen, R. C. H. (2015). Validity of at home model predictions as a proxy for personal exposure to radiofrequency electromagnetic fields from mobile phone base stations.

Environmental Research, 142, 221-226. https://doi.org/10.1016/j.envres.2015.06.029

Neubauer, G., Cecil, S., Giczi, W., Petric, B., Preiner, P., Fröhlich, J., \& Röösli, M. (2010). The association between exposure determined by radiofrequency personal exposimeters and human exposure: A simulation study. Bioelectromagnetics, 31(7), 535-545. https://doi.org/10.1002/bem.20587

Röösli, M., Frei, P., Bolte, J., Neubauer, G., Cardis, E., Feychting, M., ... Vrijheid, M. (2010). Conduct of a personal radiofrequency electromagnetic field measurement 
study: proposed study protocol. Environmental Health, 9(1).

https://doi.org/10.1186/1476-069X-9-23

Sagar, S., Adem, S. M., Struchen, B., Loughran, S. P., Brunjes, M. E., Arangua, L., ... Röösli, M. (2018). Comparison of radiofrequency electromagnetic field exposure levels in different everyday microenvironments in an international context.

Environment International, 114, 297-306.

https://doi.org/10.1016/j.envint.2018.02.036

Sagar, S., Struchen, B., Finta, V., Eeftens, M., \& Röösli, M. (2016). Use of portable exposimeters to monitor radiofrequency electromagnetic field exposure in the everyday environment. Environmental Research, 150, 289-298. https://doi.org/10.1016/j.envres.2016.06.020

Thielens, A., Agneessens, S., Verloock, L., Tanghe, E., Rogier, H., Martens, L., \& Joseph, W. (2015). On-body calibration and processing for a combination of two radiofrequency personal exposimeters. Radiation Protection Dosimetry, 163(1), 58-69. https://doi.org/10.1093/rpd/ncu056

Thielens, Arno, Van den Bossche, M., Brzozek, C., Bhatt, C. R., Abramson, M. J., Benke, G., ... Joseph, W. (2018). Representativeness and repeatability of microenvironmental personal and head exposures to radio-frequency electromagnetic fields. Environmental Research, 162, 81-96. https://doi.org/10.1016/j.envres.2017.12.017

Urbinello, D., Huss, A., Beekhuizen, J., Vermeulen, R., \& Röösli, M. (2014a). Use of portable exposure meters for comparing mobile phone base station radiation in different types of areas in the cities of Basel and Amsterdam. Science of The Total Environment, 468-469, 1028-1033. https://doi.org/10.1016/j.scitotenv.2013.09.012

Urbinello, D., Joseph, W., Huss, A., Verloock, L., Beekhuizen, J., Vermeulen, R., ... Röösli, M. (2014b). Radio-frequency electromagnetic field (RF-EMF) exposure levels in different European outdoor urban environments in comparison with regulatory limits. Environment International, 68, 49-54. https://doi.org/10.1016/j.envint.2014.03.007

Urbinello, D., Joseph, W., Verloock, L., Martens, L., \& Röösli, M. (2014c). Temporal trends of radio-frequency electromagnetic field (RF-EMF) exposure in everyday environments across European cities. Environmental Research, 134, 134-142. https://doi.org/10.1016/j.envres.2014.07.003 